ARTICLE

\title{
Retromer stabilization results in neuroprotection in a model of Amyotrophic Lateral Sclerosis
}

Luca Muzio (10 ${ }^{1 凶}$, Riccardo Sirtori ${ }^{1,6}$, Davide Gornati ${ }^{2,6}$, Simona Eleuteri ${ }^{1}$, Andrea Fossaghi ${ }^{1}$, Diego Brancaccio ${ }^{3}$, Leonardo Manzoni ${ }^{4,8}$, Linda Ottoboni (10) ${ }^{1}$, Luca De Feo ${ }^{1}$, Angelo Quattrini ${ }^{1}$, Eloise Mastrangelo ${ }^{5}$, Luca Sorrentino (1) 5, Emanuele Scalone 2,5, Giancarlo Comi ${ }^{1}$, Luciana Marinelli ${ }^{3}$, Nilo Riva ${ }^{1}$, Mario Milani (i) ${ }^{5,7}$, Pierfausto Seneci (i) ${ }^{2,7} \&$ Gianvito Martino (i) ${ }^{1,7}$

Amyotrophic Lateral Sclerosis (ALS) is a fatal disease characterized by the degeneration of upper and lower motor neurons (MNs). We find a significant reduction of the retromer complex subunit VPS35 in iPSCs-derived MNs from ALS patients, in MNs from ALS post mortem explants and in MNs from SOD1G93A mice. Being the retromer involved in trafficking of hydrolases, a pathological hallmark in ALS, we design, synthesize and characterize an array of retromer stabilizers based on bis-guanylhydrazones connected by a 1,3-phenyl ring linker. We select compound $2 \mathrm{a}$ as a potent and bioavailable interactor of VPS35-VPS29. Indeed, while increasing retromer stability in ALS mice, compound 2a attenuates locomotion impairment and increases MNs survival. Moreover, compound 2a increases VPS35 in iPSCsderived MNs and shows brain bioavailability. Our results clearly suggest the retromer as a valuable druggable target in ALS.

\footnotetext{
${ }^{1}$ INSPE-Institute of Experimental Neurology, San Raffaele Scientific Institute, Milano, Italy. ${ }^{2}$ Department of Chemistry, University of Milan, Milano, Italy. ${ }^{3}$ Department of Pharmacy, University of Naples "Federico II", Naples, Italy. ${ }^{4}$ Institute of Molecular Science and Technology (ISTM), CNR, Milan, Italy.

${ }^{5}$ Institute of Biophysics (IBF), CNR, Milan, Italy. ${ }^{6}$ These authors contributed equally: Riccardo Sirtori, Davide Gornati. ${ }^{7}$ These authors jointly supervised this work: Mario Milani, Pierfausto Seneci, Gianvito Martino. ${ }^{8}$ Deceased: Leonardo Manzoni. ${ }^{凶}$ email: luca.muzio@hsr.it
} 
A myotrophic Lateral Sclerosis (ALS) is a devastating disorder, featured by a progressive degeneration of brain and spinal cord (SC) motor neurons (MNs). Clinical outcomes involve muscle weakness, movement defects, speech disturbances, dysphasia, and eventually death by respiratory failure ${ }^{1}$. The pathobiology of ALS is not completely understood, although the presence of cytoplasmic inclusions of protein aggregates in neurons is a key hallmark of ALS pathophysiology 2 .

Most ALS patients (90\%) are sporadic, while only $\approx 10 \%$ display a positive family history (fALS). Around $20 \%$ of fALS patients show mutations in the copper/zinc superoxide dismutase (SOD1) gene $^{3}$. The ALS-linked G93A mutation of SOD1 allowed the establishment of a mouse model, featuring $\mathrm{MN}$ degeneration in the SC ${ }^{4}$. Mutant SOD1 proteins misfold, filling MNs with toxic aggregates, which impinge on their survival ${ }^{5}$. Unlike proliferating cells, which dilute aggregated proteins at each round of cell division, neurons degrade these aggregates only through the ubiquitin-proteasome system, or the autophagy-lysosomal pathway ${ }^{6}$.

Lysosomal health is crucial for the degradation of dysfunctional proteins and in particular for the clearance of autophagic vacuoles. An impaired lysosomal system contributes to autophagy stress, accumulation of damaged mitochondria, and restricts clearance of proteins aggregates. Remarkably, lysosome impairment is among the earliest pathological events that affect MNs in G93A mice ${ }^{7}$.

Delivery of proteolytic enzymes to lysosomes needs the coordinated action of multiple protein regulators, among which the highly conserved retromer complex ${ }^{8}$. The retromer complex was initially described for its ability to sort plasma membrane proteins from endosomes to the trans-Golgi network, or back to the cell surface. Two subcomplexes assemble in the cytoplasm to produce the retromer complex. The former is a trimeric complex composed by vacuolar protein sorting (VPS) 35, 29, and 26 that assemble into the cargo recognition core (CRC) complex ${ }^{9}$. The latter consists of sorting-nexin (SNX) proteins, either containing phox-homology (PX) and bin/amphiphysin/rvs (BAR) domains, or only the former one ${ }^{10-13}$. The retromer recycles specific cargos, such as Vps10/Sortilin protein family members ${ }^{14}$ or the cation-independent mannose 6-phosphate receptor (CI-MPR) ${ }^{15}$. The latter is involved in the delivery of proteolytic enzymes to lysosomes. A point mutation in VPS35 (D620N) is causative of an autosomal dominant form of Parkinson's disease (PD) ${ }^{16,17}$ and affects early steps of autophagosome formation ${ }^{18}$. VPS35 deficiency alters the distribution of lysosome-associated membrane glycoprotein $2 \mathrm{a}$ (Lamp2a) in neurons ${ }^{19}$.

Pharmacological tools, increasing the interaction between members of the CRC complex, increase retromer stability and enhance retromer-mediated trafficking of cargos. The isothiourea chaperone R55/1 stabilizes the VPS35-VPS29 interaction, increases retromer levels in vitro, and decreases pathogenic processing of APP in cells ${ }^{20}$.

We describe a substantial reduction of CRC proteins in MNs of G93A mice; a similar VPS35 downregulation in SCs from ALS patients and in inducible pluripotent stem cells (iPSCs)-derived MNs. We design, synthetize and characterize a small array of bisguanylhydrazones. Such retromer stabilizers possess good in vivo bioavailability, potency, and stability. We selected phenyl-1,3-bisguanylhydrazone $\mathbf{2 a}$ for extended in vitro and in vivo characterization in ALS models.

\section{Results}

CRC proteins are downregulated in G93A mice. A loss of Cathepsin D (CSTD) along with endo-lysosomal deficits affects $\mathrm{MNs}$ of G93A mice ${ }^{7}$. As these alterations could implicate retromer functionality ${ }^{21}$, we studied CRC proteins in SCs from G93A mice. VPS35 immunoreactivity in cultured neurons is organized in puncta that localize throughout the cell soma, dendrites, and axons ${ }^{9,22,23}$. Accordingly, immunofluorescence (IF) analysis of VPS35 ${ }^{+}$puncta showed their clustering in the soma and cytoplasmic bundles of ventral horn wild-type (WT) MNs (Fig. 1a and Supplementary Fig. 1a). VPS35 immunoreactivity was substantially attenuated in MNs of asymptomatic and symptomatic G93A mice (Fig. 1a and Supplementary Fig. 1b, c). Similarly, we observed attenuated VPS26 immunoreactivity in parallel SC sections (Fig. 1b and Supplementary Fig. 1d-f). We next assayed the levels of VPS35, VPS29, and the VPS26b isoform highly expressed in the $\mathrm{CNS}^{24}$ by western blotting lumbar SC extracts from G93A mice. We observed a significant reduction of VPS35 in asymptomatic and symptomatic G93A mice, as well as a reduction of VPS26b and VPS29 in symptomatic G93A mice (Fig. 1c-e and Supplementary Fig. 1g, h). These results confirm that a loss of any of the CRC components leads to instability and rapid degradation of the remaining proteins ${ }^{25}$. Conversely, we did not find alterations of VPS35 and VPS26 immunoreactivities in $\mathrm{NeuN}^{+}$cells sampled in the motor cortex of G93A mice (Supplementary Fig. 2a-f). We next assayed Vps35, Vps26, and Vps29 mRNAs levels in lumbar SC extracts by real-time PCR. Despite the reduction of VPS protein levels, their mRNA levels did not drop significantly when compared with WT controls, suggesting that their reduction was not caused by transcriptional inhibition (Fig. 1f).

Design and synthesis of new pharmacological chaperones. R55/ $\mathbf{1}$ binds to a characterized hot spot at the interface between VPS35 and VPS29 20 . We replaced the 2,5-disubstituted thiophene scaffold in R55/1 with a phenyl ring. Phenyl and thiophene rings are bio-isosters ${ }^{26}$, and the former offers more synthetic versatility, i.e., can be substituted for structure activity relationship (SAR) acquisition. We substituted isothioureas with guanylhydrazones, as the latter groups show good stability and a pKa range closer to neutrality due to the delocalization of their charge on three $\mathrm{N}$ atoms (favored azine form vs. disfavored hydrazone form, $4.5 \leq$ $\Delta \mathrm{GT} \leq 6.5 \mathrm{Kcal} / \mathrm{mol}^{27}$, Supplementary Fig. 3). The pKa range of guanylhydrazones should ensure a higher permeability through lipophilic bio-membranes, due to an estimated $\approx 16 \%$ free base at $37^{\circ} \mathrm{C}$ and $\mathrm{pH}=7.4^{28}$. Their presence in drugs ${ }^{29}$ endowed with blood-brain barrier (BBB) permeability ${ }^{30}$ supports our choice.

Six compounds were then studied in silico for their putative affinity for the retromer complex. Standard thiophene bisisothiourea $\mathrm{R} 55 / \mathbf{1}^{20}$, and compounds bearing one (3a-5a) or both described modifications (2a, 6a) (Fig. 2a) were studied in silico for their putative affinity for the retromer complex. Their docking site was set at the interface between VPS35 and VPS29 (PDB code: 2R17), where R55/1 binding was revealed by point mutation $^{20}$. We determined the interaction energy between each compound (best pose) and the VPS35-VPS29 interface (calculated $\mathrm{Kd}$ ). A normalized $\mathrm{Kd}$ took into account its recurrence in 40 simulation runs using a sigmoid function/multiplication factor (MF), varying between 2 (lowest recurrence, i.e., 1 in 40 poses) and 0.1 (highest recurrence, i.e., 40 in 40 poses). The function is neutral $(\mathrm{MF}=1)$ for a $50 \%$ recurrence (20 in 40 poses), and favors/penalizes compounds with high/low recurrent poses (Supplementary Fig. 4a). Figure 2b lists calculated and normalized Kd values for standard R55/1 and compounds 2a-6a, which show limited differences. We docked R55/1 (orange yellow in Fig. 2c), obtaining a calculated $\mathrm{Kd}=128.5 \mu \mathrm{M}$ and a normalized $\mathrm{Kd}=189.0 \mu \mathrm{M}$ (15/40 poses). Its best docking pose suggested a thiophene-benzene ring replacement filling a small surface recess surrounded by the Phe541 residue in VPS35, and by Tyr139 and 

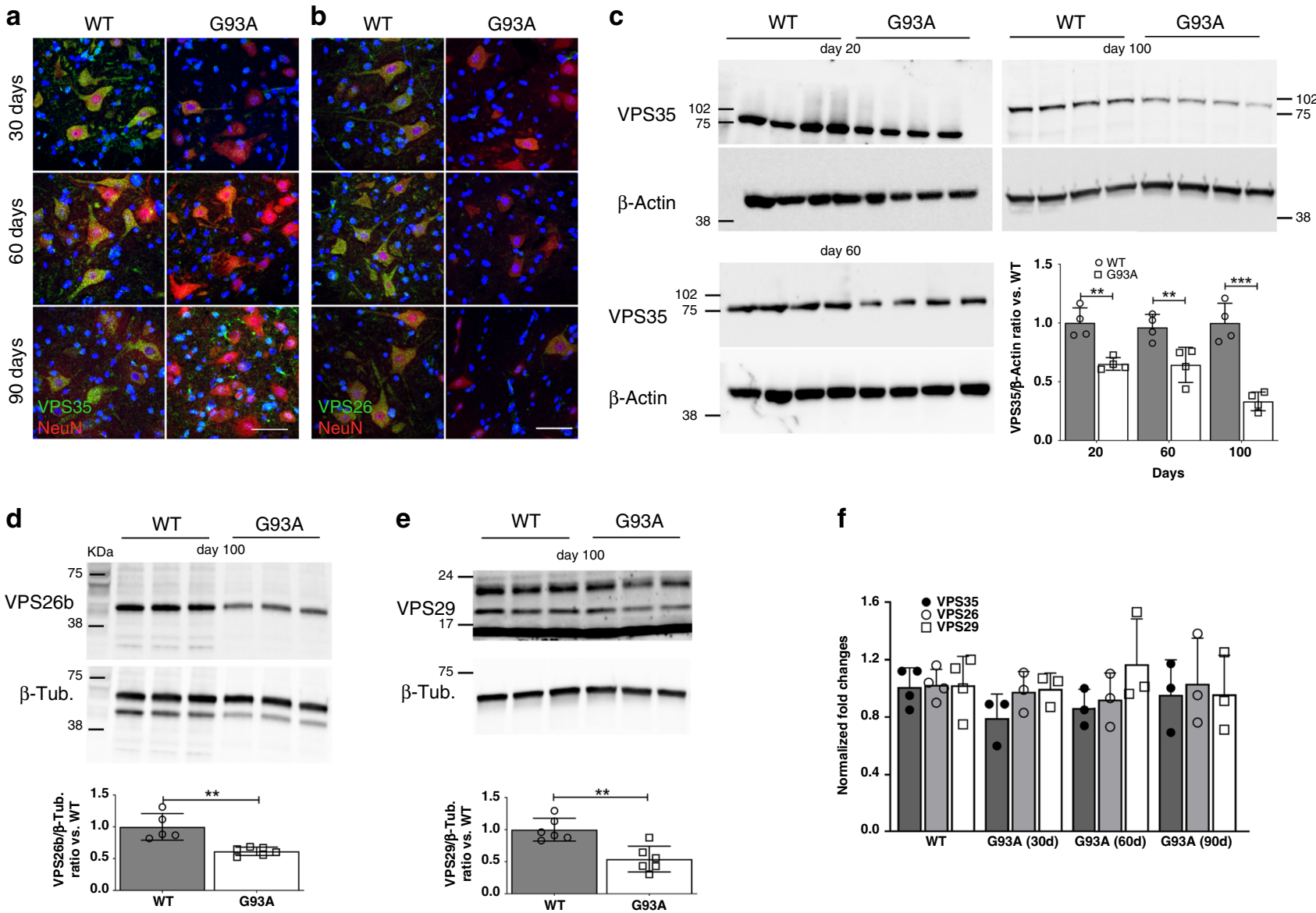

f

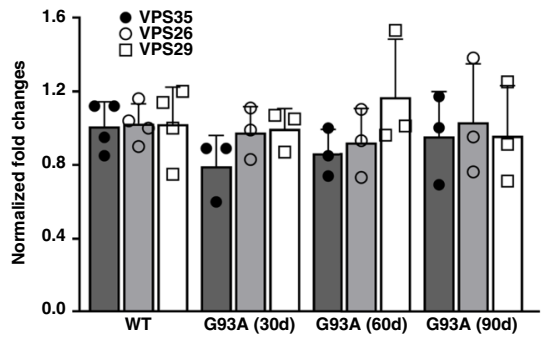

Fig. 1 CRC proteins are downregulated in G93A MNs. a Maximal projections of confocal stacks of VPS35 $5^{+} \mathrm{NeuN}^{+}$putative MNs in the ventral horn of lumbar SCs from WT and G93A mice (30, 60 and 90 days, $n=4$ biologically independent mice/time point). Adjacent sections labelled for VPS26 and NeuN are shown in $\mathbf{b},(30,60$ and 90 days, $n=4$ biologically independent mice/time point). $\mathbf{c}$ WBs for VPS35 and $\beta$-Actin in lumbar SCs protein extracts from WT and G93A mice at 20,60, and 100 days ( $n=4$ biologically independent mice/time point). The histogram shows quantifications (mean \pm SD) of normalized VPS35 levels (ratio versus WT), (WT vs. G93A day20: $p=0.007$; day 60: $p=0.0015$; day 90: $p<0.0001$ ). d Representative WB for VPS26b and $\beta$-Tubulin in SCs from WT and G93A mice at day 100. The histogram shows the quantification (mean \pm SD) of normalized VPS26b levels (ratio versus WT, $n=5$ biologically independent WT mice and $n=6$ biologically independent G93A mice, $p=0.002$ ). e Representative WB for VPS29 levels in SCs from WT and G93A mice at day 100. The histogram shows the quantification (mean \pm SD) of normalized VPS29 levels (ratio versus WT, $n=6$ biologically independent mice/group, $p=0.0019$ ). $\mathbf{f}$ quantification of Vps35, Vps26, and Vps29 mRNAs by real-time PCR (ratio versus WT) in lumbar SCs from WT (sampled at day $60, n=4$ biologically independent mice) and G93A mice (30, 60, and 90 days, $n=3$ biologically independent mice/time point). Two-way ANOVA followed by Bonferroni multiple comparisons test was used to analyze data of $\mathbf{c}$. Two-tailed Student's $t$-test was used to determine the statistical significance in $\mathbf{d}$ and e. One-way ANOVA followed by Tukey's Multiple Comparison test was used to analyze data of $\mathbf{f} .{ }^{\star \star} p<0.01 ;{ }^{\star \star \star} p<0.001$. Scale bar $80 \mu \mathrm{m}$.

Thr144 residues in VPS29 (surface recess 1, Fig. 2c). Therefore, we modelled either a 1,3-(meta, compound 4a, yellow in Fig. 2d) or a 1,4-phenyl bis-isothiourea (para, compound 5a, light blue in Fig. 2d). In silico docking suggested that meta-substitution should preserve the favorable geometry of R55/1, slightly improving the interaction with surface recess 1 (calculated $\mathrm{Kd}=82.1 \mu \mathrm{M}$ for $4 \mathrm{a}$ ) with good recurrence (normalized $\mathrm{Kd}=27.5 \mu \mathrm{M}-29 / 40$ poses). Para substitution showed a reduced interaction (calculated $\mathrm{Kd}=$ $290.6 \mu \mathrm{M}$ ) with low recurrence (normalized $\mathrm{Kd}=561 \mu \mathrm{M}-7 / 40$ poses) through repositioning of an isothiourea group in $\mathbf{5 a}$ toward another surface cavity (surface recess 2 , Fig. 2 d), and the loss of electrostatic interactions with Glu545. We then replaced isothioureas with two meta-guanylhydrazones (compound 3a, violet in Fig. 2e), showing a pose similar to R55/1, with improved affinity (calculated $\mathrm{Kd}=9.2 \mu \mathrm{M}$ ) and good recurrence (normalized $\mathrm{Kd}=5.1 \mu \mathrm{M}-25 / 40$ poses). When phenyl and 1,3 guanylhydrazones were introduced in compound 2a (gray in Fig. 2e and Supplementary Fig. 4b, e-g), it displayed a favorable orientation with the phenyl ring filling surface recess 1, further increasing affinity for the putative binding site (calculated $\mathrm{Kd}=1.8 \mu \mathrm{M}$ ) with high recurrence (normalized $\mathrm{Kd}=0.53 \mu \mathrm{M}-35 / 40$ poses). The good interaction of phenyl-1,4 guanylhydrazone (compound 6a, calculated $\mathrm{Kd}=3.8 \mu \mathrm{M}$ ) was penalized by its low recurrence (normalized $\mathrm{Kd}=7.1 \mu \mathrm{M}-9 / 40$ poses).

The predicted partition coefficient ( $\log \mathrm{P}$-bioavailability) and $\mathrm{pKa}$ values (neutral/charged ratio at physiological $\mathrm{pH}$ ) were calculated for compounds $\mathbf{2 a - 6 a}$, and standard R55/1. $\log P$ values around 2.1 were suggested for isothioureas $\mathbf{1}, \mathbf{4 a}$, and $\mathbf{5 a}$, while values around 0 were suggested for guanylhydrazones $2 \mathbf{a}$, 3a, and 6a. Both values are aligned with Lipinski rules ${ }^{31}$, supporting bioavailability for both compound families. Conversely, predicted $\mathrm{pKa}$ values were lower for guanylhydrazones $\mathbf{2 a}$, $\mathbf{3 a}$, and $\mathbf{6 a}(\mathrm{pKa} 1 \approx 7.5, \mathrm{pKa} 2 \approx 8.1)$ than for isothioureas $\mathbf{1}, \mathbf{4 a}$, and $5 \mathrm{a}(\mathrm{pKa} 1 \approx 10.2, \mathrm{pKa} 2 \approx 10.8)$, suggesting a higher abundance of neutral, BBB-permeable guanylhydrazones at physiological $\mathrm{pH}$.

We synthesized compounds 2a-6a through short, highyielding strategies: isothioureas $\mathbf{4 a}$ and $\mathbf{5 a}$ from dichloromethylbenzenes and isothiourea (Supplementary Fig. 4c); phenyl 
a

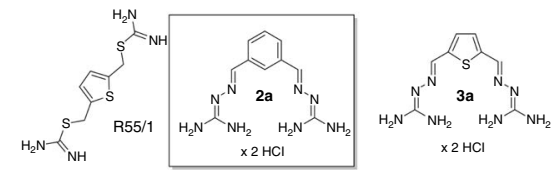

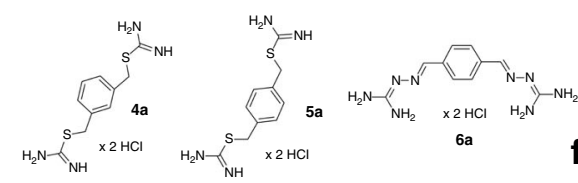

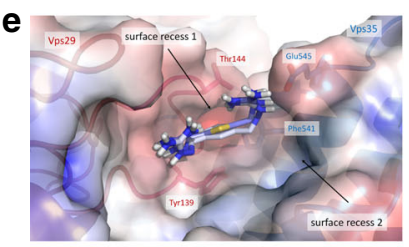

b

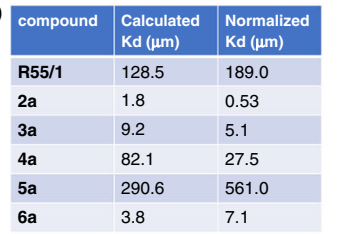

VPS35 75
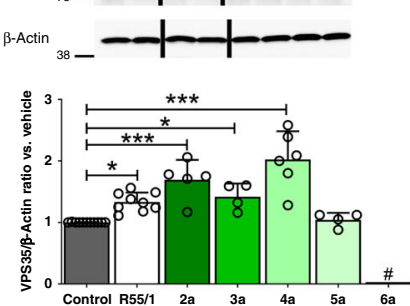

h

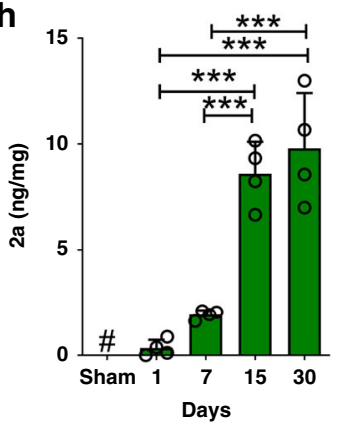

i

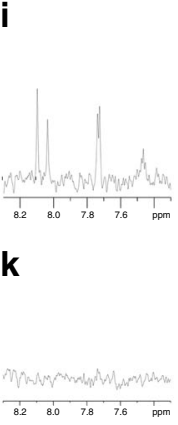

j
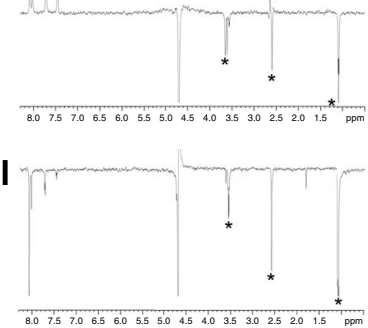

c

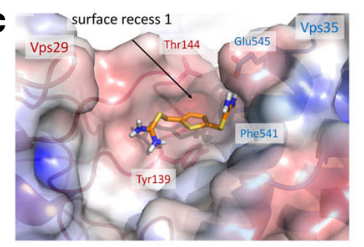

d

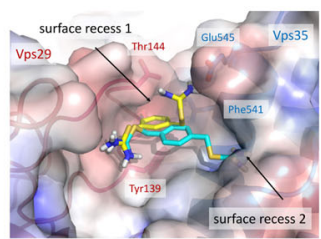

g
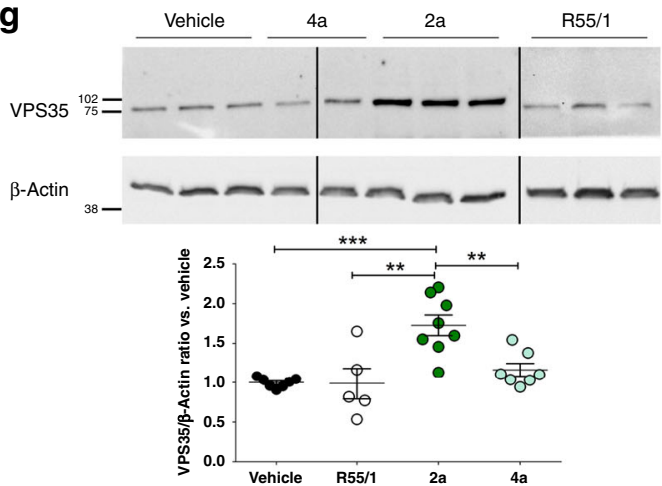

m

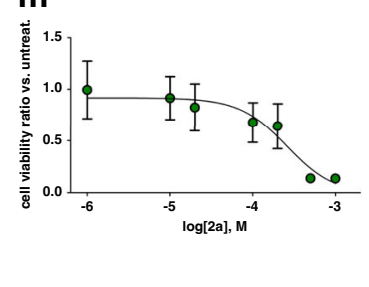

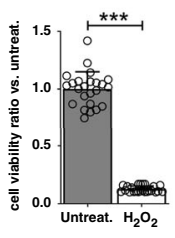

Fig. 2 Structure and binding modes for R55/1 and compounds $\mathbf{2 a - 6 a}$ a Standard R55/1, compounds bearing one (3a-5a) or two modifications (2a, 6a), $\mathbf{b}$ Calculated and normalized Kd values for compounds 2a-6a. c R55/1 (orange carbons atoms) positioned near a small cavity (surface recess 1 ) outlined by Tyr139 and Thr144 in VPS29, and Phe541 in VPS35. d 1,3-meta substituted 4a (yellow carbon atoms) better fits into surface recess 1; 1,4-meta substituted 5a (cyan carbon atoms) repositions an isothiourea group in surface recess 2, with a predicted loss of affinity. e docking poses of 1,3-phenyl bis-isothiourea 3a (violet carbon atoms) and 1,3-phenyl bis-guanylhydrazone 2a (grey carbon atoms) in their putative binding site. $\mathbf{f}$ representative WB for VPS35 and $\beta$ Actin in treated Neuro2a cells $\left(10 \mu \mathrm{M}, 48 \mathrm{~h}, 3 \times 10^{5}\right.$ cells/well). Dividing black lines mark lanes cropped from the same filter. The histogram shows quantifications (control: $n=11$ independent wells; R55/1: $n=9$ independent wells; $2 \mathbf{a}: n=5$ independent wells; 3a: $n=4$ independent wells; $\mathbf{4 a}$ : $n=6$ independent wells; 5a: $n=4$ independent wells; $\mathbf{6 a}: n=4$ independent wells). Control vs. R55/1: $p=0.036$, control vs. 2a: $p<0.0001$, control vs. 3a: $p=$ 0.048, control vs. 4a: $p<0.0001$. $\mathbf{g}$ representative WB for VPS35 and $\beta$-Actin in SCs extracts from vehicle-, R55/1-, 2a- and $\mathbf{4 a - t r e a t e d ~ ( 1 0 ~ m g / k g ~ f o r ~}$ 7 days) C57BL/6J mice. Dividing black lines mark lanes cropped from parallel filters. The histogram shows quantifications (mean ratio \pm SD, vehicle: $n=7$ independent mice; R55/1: $n=5$ independent mice; 2a: $n=8$ independent mice; $\mathbf{4 a :} n=7$ independent mice. Vehicle vs. 2a $p<0.0001$, R55/1 vs. 2a $p=$ 0.002 , 2a vs.4a $p=0.0012)$. h Brain uptake of compound $2 \mathrm{a}$ in C57BL/6J mice injected $(10 \mathrm{mg} / \mathrm{kg})$ with $\mathbf{2 a}(1,7,15$, and 30 days, $n=4$ independent mice/time point, mean \pm SD, $p<0.0001)$. i-I STD-NMR (i, $\mathbf{k})$ and WL $(\mathbf{j}, \mathbf{I})$ spectra of $\mathbf{2 a}(500 \mu \mathrm{M})$. Spectra (i) and (j) are in presence of VPS29-VPS35 complex $(10 \mu \mathrm{M})$, spectra $(\mathbf{k})$ and $(\mathbf{I})$ are controls. Stars indicate the proton resonances of the buffer. $\mathbf{m}$ Neuro2a cell viability (mean \pm SD, reported as ratio versus controls) in presence of increasing amounts of $\mathbf{2 a}\left(1-1000 \mu \mathrm{M}, 48 \mathrm{~h}, 4 \times 10^{4}\right.$ cells/well, $n=24$ independent wells/group, three experiments). Nonlinear fitting shows an $\mathrm{LD}_{50}$ of $257.9 \mu \mathrm{M}$. Controls were established by $\mathrm{H}_{2} \mathrm{O}_{2}$ treatment $(200 \mu \mathrm{M}$ for $48 \mathrm{~h}, n=24$ independent wells/group, untreated vs. $\mathrm{H}_{2} \mathrm{O}_{2}: p<0.0001$ ). One-way ANOVA followed by Tukey's Multiple Comparison test was used to analyze $\mathbf{f}, \mathbf{g}$, and $\mathbf{h}$ plots. Two-tailed Student's $t$-test was used to analyze data from $\mathbf{m} .{ }^{\star} p<0.05,{ }^{\star \star} p<0.01,{ }^{\star \star \star} p<0.001$.

guanylhydrazones 2a, 3a, and $\mathbf{6 a}$ from aryl dialdehydes and aminoguanidine (Supplementary Fig. 4d). We incubated Neuro2a cells with compounds $2 \mathbf{a}-\mathbf{6 a}(10 \mu \mathrm{M})$ or with standard R55/1 (10 $\mu \mathrm{M})$ for $48 \mathrm{~h}$. Protein extracts were collected, separated by SDSPAGE and immunoblotted for VPS35 and the housekeeping gene $\beta$-Actin. We observed limited cytotoxicity in cells receiving compound $\mathbf{6 a}$ that prevented the measurement of their VPS35 levels. As expected, VPS35 levels increased in R55/1-treated cells ${ }^{20}$. Similarly, compounds $\mathbf{2 a}, \mathbf{3 a}$, and $\mathbf{4 a}$ increased VPS35 levels, while compound 5a did not (Fig. 2f). Compound 2a displays the lowest $\mathrm{Kd}$ value among molecules $\mathbf{2 a - 6 a}$, and we checked whether it could increase VPS26b and VPS29 levels. Accordingly, VPS26b and VPS29 proteins were significantly increased by compound 2a in Neuro2a cells after treatment for $48 \mathrm{~h}$ (Supplementary Fig. 5a).

In vivo delivery of compound $2 \mathrm{a}$ to the brain. Compounds $2 \mathrm{a}$, 4a, and standard $\mathrm{R} 55 / \mathbf{1}(10 \mathrm{mg} / \mathrm{Kg})$ were intraperitoneally injected in C57BL6J mice daily. After 1 week, mice were sacrificed, saline perfused to avoid CNS contamination by compounds in blood circulation, and SC protein extracts were assayed by WB. While treatment with isothiourea 4a slightly, but not significantly, increased VPS35 levels, phenyl-1,3-guanylhydrazone 2a significantly increased VPS35 levels in SC extracts (Fig. 2g). Pharmacokinetic analysis of C57BL6J brains receiving daily 
intraperitoneal injections of compound 2a confirmed its access to the CNS (Fig. 2h). Therefore, phenyl-1,3-bis-guanylhydrazone 2a was selected as an early lead.

NMR studies. We used a ligand-based NMR approach to localize the binding between compound 2a and the VPS29-VPS35 heterodimer. These techniques provide binding information without requiring any isotopic labeling of the proteins. Particularly, Saturation Transfer Difference NMR (STD-NMR) ${ }^{32}$ and WaterLogsy-NMR (WL-NMR) ${ }^{33}$ experiments were acquired in buffer solutions containing a large excess of compound 2a $(500 \mu \mathrm{M})$ with respect to VPS29-VPS35 $(10 \mu \mathrm{M})$. Both STD-NMR and WL-NMR focus on the NMR signals of the ligand and utilize the magnetization transfer by the Nuclear Overhauser Effect (NOE) between protein and ligand. STD-NMR experiments are carried out by subtraction of a $1 \mathrm{D}^{1} \mathrm{H}$ spectrum where the protein protons are selectively irradiated (on-resonance spectrum) from a spectrum in which the protein is not saturated (off-resonance spectrum). The resulting STD spectrum only shows ligand proton signals in contact with the macromolecule. The STD-NMR spectrum (Fig. 2i) shows the aromatic signals of compound $2 \mathbf{a}$ in presence of the VPS29-VPS35 heterodimer, strongly indicating an interaction between the ligand and the protein complex.

WL-NMR entails magnetization transfer to the ligand from either bulk water via a macromolecule, and/or the exchangeable protons and the water molecules present in the binding site. Positive peaks for proton resonances of the ligand in the WLNMR spectrum are observed for binders in presence of the protein. Otherwise, negative peaks will indicate that a putative ligand does not interact with the macromolecule. In the WLNMR spectrum (Fig. 2j) the aromatic signals of compound $\mathbf{2 a}$ in presence of the VPS29-VPS35 heterodimer show positive peaks, while proton resonances of the buffer (highlighted with stars in Fig. $2 \mathrm{j}, \mathrm{l}$ ) show a negative phase, indicating that $\mathbf{2 a}$ binds to the protein complex. As negative control, STD-NMR and WL-NMR experiments were performed for compound $\mathbf{2 a}$ in absence of the heterodimer. The absence of proton signals in the aromatic zone and the presence of negative signals in STD-NMR (Fig. 2k) and WL-NMR (Fig. 2l) spectra, respectively, confirms the binding between compound $\mathbf{2 a}$ and the VPS29-VPS35 heterodimer. Unfortunately, STD- and WL-NMR competition experiments between $2 \mathbf{a}$ and R55/1 could not be performed since the latter compound was not stable in our experimental conditions.

Compound 2a increases VPS35 levels. We next measured VPS35 degradation rates by a cycloheximide ( $\mathrm{CHX}$ ) chase assay. Neuro2a cells received vehicle or compound $2 \mathrm{a}(10 \mu \mathrm{M})$ for $24 \mathrm{~h}$, then CHX was added and VPS35 levels were measured by WB. As reported $^{34}$, we observed that vehicle-treated cells exhibited a drop of VPS35 levels $(\sim 40 \%)$ after $8 \mathrm{~h}$ of CHX treatment. Conversely, pretreating cells with compound $\mathbf{2 a}$ protected VPS35 from degradation (Supplementary Fig. 6a, b).

Compound $\mathbf{2 a}$, as $\mathrm{R} 55 / \mathbf{1}^{20}$, did not influence the transcription levels of CRC genes in Neuro2a cells, as determined by measuring Vps35, Vps26, and Vps29 mRNAs levels by real-time PCR (Supplementary Fig. 6c).

We assessed the cytotoxicity of compound $\mathbf{2 a}$, measuring survival of Neuro2a cells exposed to increasing 2 a concentrations. The calculated $\mathrm{LD}_{50}$ was $\sim 260 \mu \mathrm{M}$ (Fig. $2 \mathrm{~m}$ ), a higher value than the concentration needed to stabilize the retromer in vitro. We next checked for toxic effects of compound 2a in primary neuronal cultures coupled with Micro Electrode Array (MEA) devices. Mouse cortical neurons (E16.5) were plated on MEAs, kept in culture for 14 days to develop firing activity and recorded in presence of $2 \mathbf{a}$. Low concentrations of compound $2 \mathbf{a}$ did not alter neuronal firing, while we observed a slight reduction of spikes only when neurons were incubated with $100 \mu \mathrm{M}$ of $\mathbf{2 a}$ (Supplementary Fig. $7 \mathrm{a}-\mathrm{c}$ ). These results indicate a wide therapeutic window for compound $2 \mathrm{a}$, considering the low $\mu \mathrm{M}$ concentration needed in vitro to increase VPS35 levels.

\section{Compound 2a counteracts SOD1 ${ }^{\mathrm{G} 93 A}$-mediated cytotoxicity.}

The Golgi apparatus is affected in MNs from ALS patients and in cells overexpressing mutant SOD1 forms ${ }^{35-37}$. We transiently transfected Neuro2a cells with plasmids encoding SOD1G93A before treatment with compound $2 \mathbf{a}$. Confocal analysis of cells labelled for trans-Golgi network marker Golgin97 revealed that many SOD1G93A+ cells displayed trans-Golgi fragmentation. Compound 2a significantly reverted this phenotype (Fig. 3a). We next determined the viability of Neuro2a cells transfected with SOD $1^{G 93 A}$ and exposed to compound 2 a using a colorimetric assay. Controls cells received $\mathrm{LacZ}$ plasmids. Compound $2 \mathrm{a}$ (10 $\mu \mathrm{M}, 48 \mathrm{~h}$ ) did not affect cell survival (Fig. $2 \mathrm{l}$ and Fig. 3b). We observed a slight, but not significant, reduction of cell viability in LacZ-transfected Neuro2a cells (Fig. 3b). When SOD1 ${ }^{G 93 A}$ was overexpressed, cell viability was greatly reduced. Notably, cell viability was restored in $S O D 1^{G 93 A_{\text {-transfected and compound }}}$ 2a-treated Neuro2a cells (Fig. 3b). The increased cell viability provided by compound 2a could result from unknown, nonspecific off-target effects. Therefore, we used plasmids encoding VPS35 to increase/stabilize the retromer complex. Overexpression of VPS35 did not affect Neuro2a cell viability, while SOD1 ${ }^{G 93 A}$ greatly affected their survival (Fig. 3c). However, this phenotype was reverted co-transfecting VPS35 and SOD1 ${ }^{G 93 A}$ plasmids (Fig. 3c).

Having observed a marked improvement of viability in

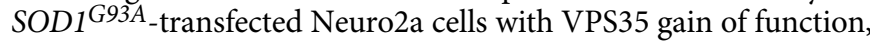
we investigated the effect of VPS35 loss of function. We transfected Neuro2a cells with RNAi plasmids encoding a siRNA duplex for VPS35, to knockdown VPS35 and disrupt the retromer assembly ${ }^{38}$. The Sh56 plasmid significantly reduced VPS35 protein and mRNA levels and VPS35 immunoreactivity in cells, when compared with a scramble plasmid (Supplementary Fig. 8a-e). Downregulation of VPS35 by Sh56-encoding plasmids did not affect Neuro2a cell survival (Fig. 3d). As previously shown, cells receiving SOD1 ${ }^{G 93 A}$ plasmids displayed a significant reduction of cell viability. By including Sh56 plasmids in the transfection mix, we worsened this phenotype (Fig. 3d). Notably, incubation of SOD1 ${ }^{\text {G93A }}$-Sh56 double transfected cells with compound 2 a modestly increased cell viability, confirming that compound 2 a counteracts $\mathrm{SOD} 1 \mathrm{G} 93 \mathrm{~A}$-mediated cytotoxicity by increasing VPS35 levels and retromer functionality. We next assayed cytotoxicity by measuring lactate dehydrogenase (LDH) release with a $\mathrm{LDH}-\mathrm{Glo}^{\mathrm{Tm}}$ cytotoxicity assay. Cells were treated with plasmids encoding SOD $1^{G 93 A}$ and the Sh56-RNAi sequence with or without compound $\mathbf{2 a}$, while supernatants were used to measure LDH contents. Overexpression of SOD1 ${ }^{G 93 A}$ increased $\mathrm{LDH}$ release by Neuro2aA cells, when compared with control cells (Fig. 3e). Compound 2a significantly reduced $\mathrm{LDH}$ release in cells transfected with $S O D 1^{G 93 A}$, while LDH increased when cells received $S O D 1^{G 93 A}$ and Sh56 plasmids. Interestingly, high $\mathrm{LDH}$ release was observed in Neuro2a cells transfected with SOD1 ${ }^{G 93 A}$ and Sh56 plasmids and treated with compound 2a, further confirming that $\mathbf{2 a}$ counteracts $\mathrm{SOD} 1^{\mathrm{G} 93 \mathrm{~A}}$-mediated cytotoxicity by targeting the retromer (Fig. 3e).

Compound 2a ameliorates the phenotype of G93A mice. We administered compound $\mathbf{2 a}(10 \mathrm{mg} / \mathrm{kg}$, i.p.) daily to G93A and WT littermates between day 30 and day 100 . We observed a slight, but not significant reduction of body weight in both WT 


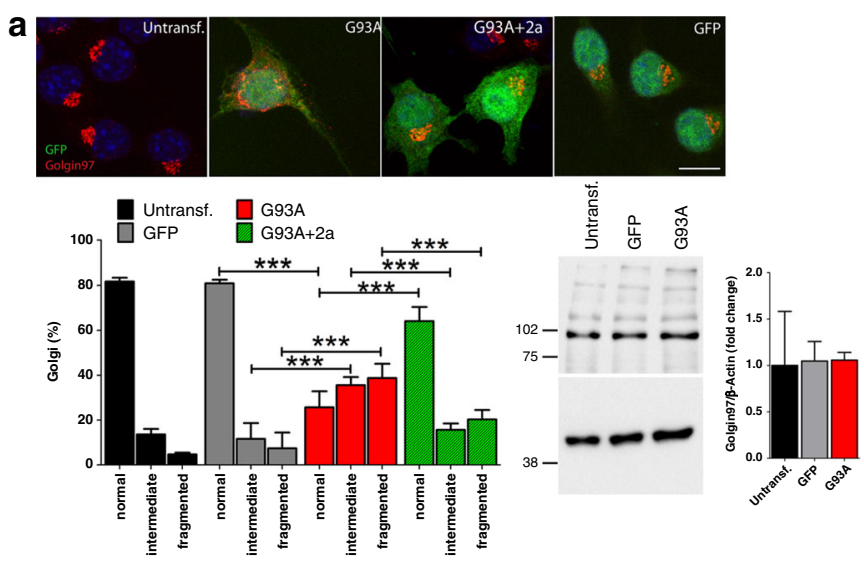

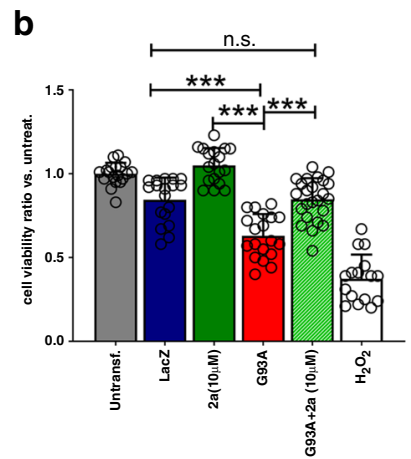

C

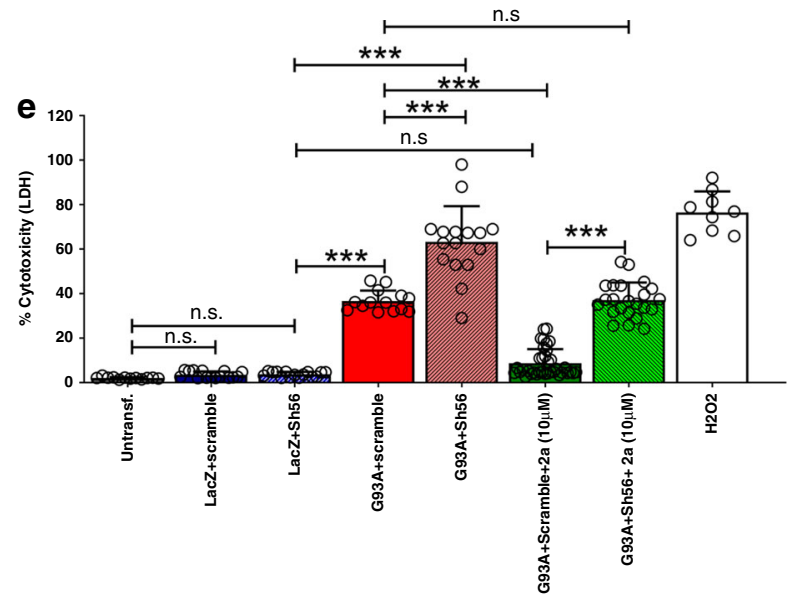

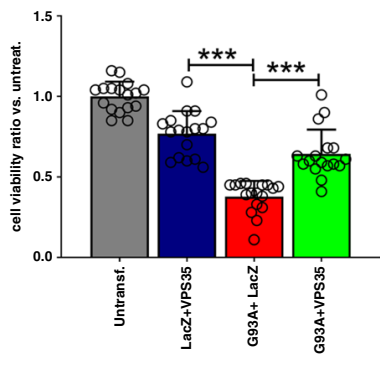

d

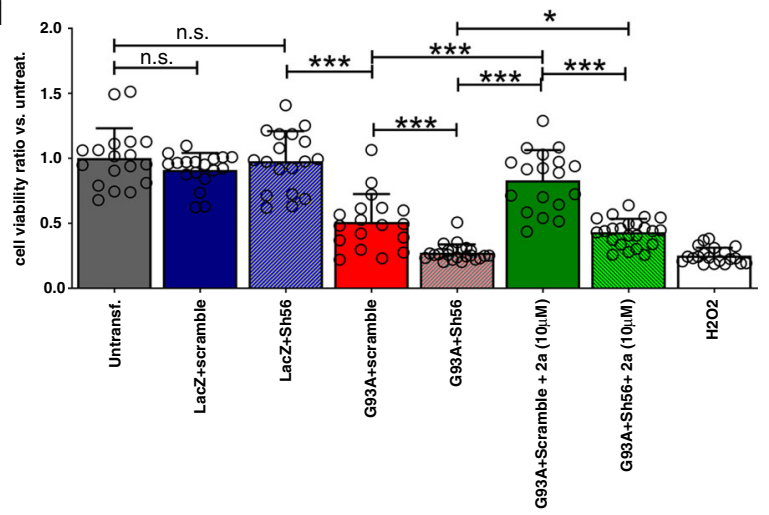

Fig. 3 Compound 2a counteracts G93A-mediated Golgi fragmentation. a merged confocal stacks for GFP and Golgin97 in untransfected-; pcDNA3.1(+) SOD1G93A (1 $\mu \mathrm{g} /$ well)-pCAAG-GFP $(0.2 \mu \mathrm{g} /$ well)-; pcDNA3.1(+)SOD1G93A $(1 \mu \mathrm{g} /$ well)-pCAAG-GFP $(0.2 \mu \mathrm{g} /$ well $)+\mathbf{2 a}(10 \mu \mathrm{M})-$ and pCAAG-GFP $(1.2$ $\mu \mathrm{g} /$ well)-transfected Neuro2a $\left(4 \times 10^{4}\right.$ cells/well). Morphological analysis of Golgi in normal, intermediate or fragmented was done in nontransfected cells ( $n=83$ independent cells), G93A-GFP ( $n=88$ independent cells), G93A-GFP+ 2a ( $n=84$ independent cells), and GFP ( $n=109$ independent cells). The histogram in panel a shows Golgi subclasses (\% of the total number of Golgi constructs, means $\pm \mathrm{SD}$ ) examined over four independent experiments, $p<$ 0.0001 for all comparisons. Protein lysates from nontransfected and transfected Neuro2a cells $\left(3 \times 10^{5}\right.$ cells/well, pcDNA3.1( + )SOD1G93A $(2 \mu \mathrm{g} /$ well)pCAAG-GFP $(0.5 \mu \mathrm{g} /$ well) or with pCAAG-GFP $(2 \mu \mathrm{g} /$ well) were immunoblotted with antibodies against Golgin97 and $\beta$-Actin. The histogram shows quantifications (mean fold changes \pm SD versus untreated cells, $n=3$ wells/group). b Neuro2a cell viabilities (mean ratio \pm SD compared to untransfected

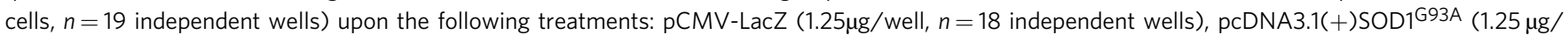
well, $n=18$ independent wells), pcDNA3.1(+)SOD1G93A (1.25 $\mu \mathrm{g} /$ well $)+\mathbf{2 a}(10 \mu \mathrm{M}, n=24$ independent wells), and $\mathbf{2 a}$ (10 $\mu \mathrm{M}, n=18$ independent wells), $\left(4 \times 10^{4}\right.$ cells/well). Controls were obtained treating Neuro2A cells with $\mathrm{H}_{2} \mathrm{O}_{2}(200 \mu \mathrm{M}, n=16$ independent wells). Data are examined over three independent experiments (LacZ vs. G93A+2a $p>0.99 ; p<0.0001$ for the other comparisons). c Neuro2a cell viabilities (mean ratio \pm SD versus untreated cells) upon the following treatments: pCMV-LacZ+pcCDNA3.1-VPS35 $(1 \mu \mathrm{g} /$ well $+0.25 \mu \mathrm{g} /$ well); pcDNA3.1 $(+)$ SOD 1 G93A + pCMV-LacZ $(1 \mu \mathrm{g} /$ well + $0.25 \mu \mathrm{g} /$ well $)$ and pcDNA3.1(+)SOD1G93A+pcCDNA3.1(+)VPS35 $(1 \mu \mathrm{g} /$ well $+0.25 \mu \mathrm{g} /$ well $),\left(4 \times 10^{4}\right.$ cells/well $) ; n=17$ biologically independent wells/ group examined over three independent experiments ( $p<0.0001$ for all comparisons). $\mathbf{d}$ Neuro2a cell viabilities (mean ratio \pm SD versus untreated Neuro2a, $4 \times 10^{4}$ cells/well, $n=18$ independent wells) upon the following treatments: pCMV-LacZ ( $1 \mu \mathrm{g} /$ well, $n=18$ independent wells) with scramble or with Sh56 plasmids $(0.25 \mu \mathrm{g} /$ well each, $n=18$ independent wells); pcDNA3.1(+)SOD1G93A ( $1 \mu \mathrm{g} /$ well) with scramble $(n=18$ independent wells) or with Sh56 plasmids ( $0.25 \mu \mathrm{g} /$ well, $n=23$ independent wells) and with or without compound $\mathbf{2 a}$ (10 $\mu \mathrm{M}, n=18$ independent wells); data are examined over three independent experiments (Untrans. vs LacZ+scramble $p=0.72$, Untrans. vs. LacZ+Sh56 $p=0.99, \mathrm{G} 93 \mathrm{~A}+\mathrm{Sh} 56$ vs. G93A+Sh56+2a $p=0.036, p<$ 0.0001 for the other comparisons). e LDH assay in Neuro2a ( $4 \times 10^{4}$ cells/well) receiving treatments and conditions as in panel d. Cytotoxicity (mean $\% \pm$ SD) was calculated by measuring amounts of LDH released in the supernatant (Untransf.: $n=12$ independent wells, LacZ+scramble and LacZ+Sh56: $n=$ 15 independent wells; G93A+scramble: $n=14$ independent wells; G93A+Sh56: $n=16$ independent wells; G93A+scramble+2a: $n=36$ independent wells; G93A+Sh56+2a: $n=23$ independent wells, $\mathrm{H}_{2} \mathrm{O}_{2}: n=9$ independent wells); data are examined over three independent experiments (Untrans. vs LacZ +scramble $p=0.99$, Untrans. vs. LacZ+Sh56 $p=0.98$ G93A+scramble vs. G93A+Sh56+2a $p=0.73, p<0.0001$ for the other comparisons). Two-way ANOVA followed by Bonferroni multiple comparisons test was used to analyze data of panel a. One-way ANOVA followed by Tukey's Multiple Comparison test was used to analyze data of $\mathbf{b}-\mathbf{e} .{ }^{\star} p<0.05,{ }^{\star \star \star} p<0.001$, n.s. not significant. Scale bar in $\mathbf{a}, 10 \mu \mathrm{m}$.

and G93A mice (Fig. 4a). We did not observe alterations of locomotion performances in WT mice treated with compound 2a (Fig. 4b). We also did not observe distress or undesirable pain. Strikingly, the progression of motor deficits in G93A mice was significantly slowed down by compound 2a (Fig. 4c). Histopathological analysis of lumbar SCs showed more MNs in ventral horns of SCs from compound 2a-treated G93A mice than from vehicle-treated G93A mice (Fig. 4d, e). We next assessed the pathological degeneration of fibers in sciatic nerves of G93A mice treated with compound 2a. We observed axonal degeneration, with a substantial reduction of myelinated nerve fibers in vehicletreated G93A mice (Fig. 5a, b) ${ }^{39}$. Conversely, mice treated with compound 2a showed a $\sim 30 \%$ reduction of degenerating fibers (Fig. 5c, d). Using Luxol Fast Blue (LFB) to label lipoproteins of the myelin sheath ${ }^{40}$, we analyzed myelination. Compound $2 \mathbf{a}$ treated G93A mice displayed a substantial reduction of 

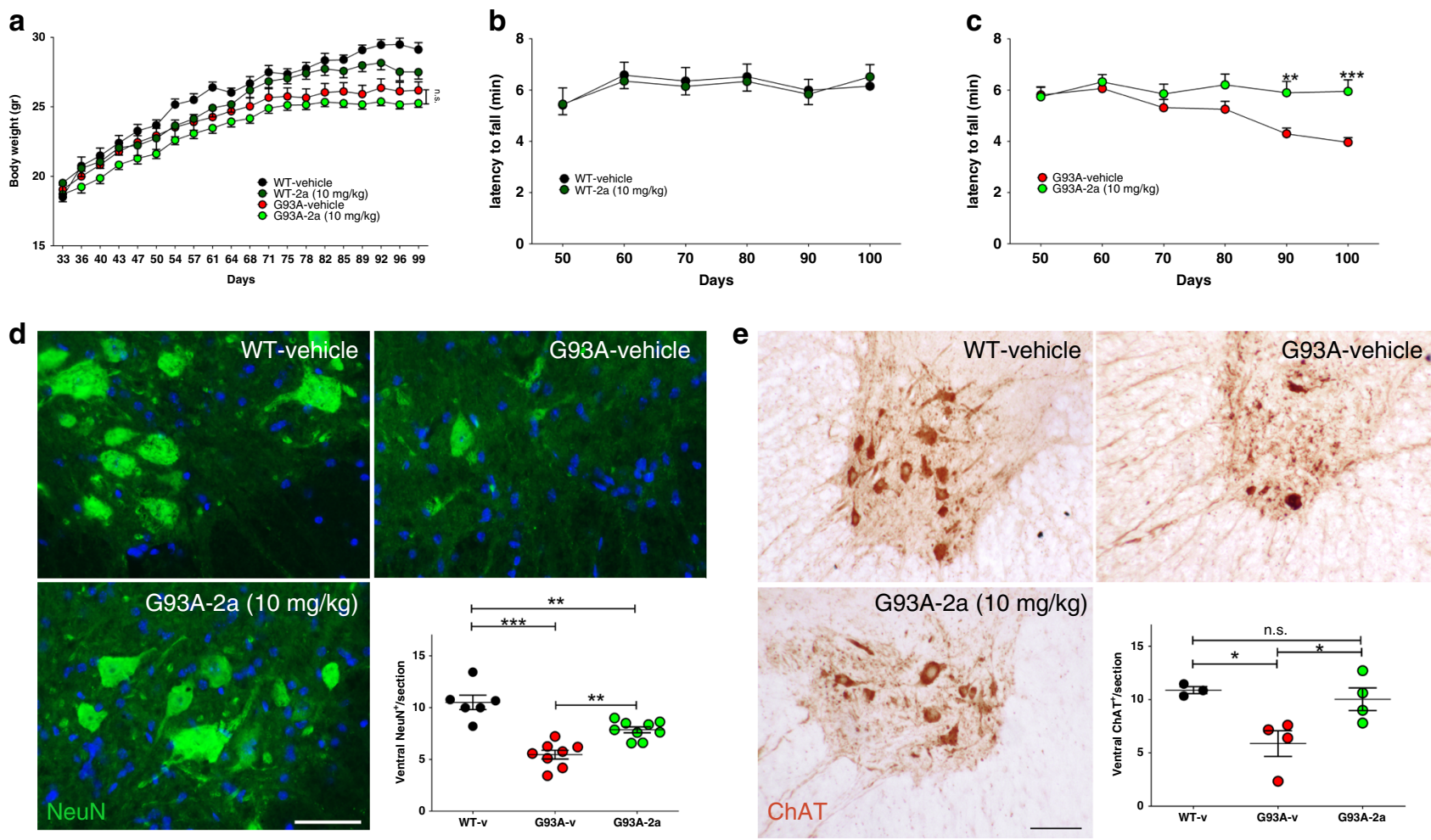

Fig. 4 Compound 2a increases locomotion of G93A mice and MNs survival. a Body weight curves measured every 3 days in vehicle-treated WT mice ( $n$ $=10$ independent mice); vehicle-treated G93A mice ( $n=15$ independent mice); compound 2a-treated WT mice $(n=10$ independent mice) and compound 2a-treated G93A mice ( $n=16$ independent mice). Data (mean \pm SEM) are examined over two independent experiments. $\mathbf{b}$ Latency to fall on the rotating bar of a rotarod apparatus in vehicle- and compound 2a-treated WT mice ( $n=10$ independent mice/group from two independent experiments). Data are reported as mean \pm SEM. c Latency to fall in vehicle- and in compound 2a-treated G93A mice $(n=15$ independent mice and $n=16$ independent mice, respectively). Data (mean \pm SEM) are examined from two independent experiments (G93A-v vs. G93A-2a day $90 p=0.0041$, day 100 $p=0.0006$ ). d Lumbar SCs sections from vehicle-treated WT mice, vehicle-treated G93A mice and compound 2a-treated G93A mice (10 mg/kg, sampled at day 100) labelled for NeuN. Quantifications were done in the ventral horn of the SC scoring MNs (WT-v: $n=6$ independent mice, G93A-v: $n=9$ independent mice, G93A-2a: $n=9$ independent mice; lines show means \pm SEM and are examined from two independent experiments). WT-v vs. G93A-v $p<0.0001$, WT-v vs. G93A-2a $p=0.0017$, G93A-v vs. G93A-2a $p=0.002$. e IHC for ChAT on lumbar SCs sections. Quantifications of $\mathrm{ChAT}^{+} / \mathrm{section}$ in the ventral horn of the SC are shown in the histogram (WT-v: $n=3$ independent mice, G93A-v: $n=4$ independent mice, G93A-2a: $n=4$ independent mice; lines show means \pm SEM and are examined from one experiment). WT-v vs. G93A-v $p=0.026$, WT-v vs. G93A-2a $p=0.84$, G93A-v vs. G93A-2a $p=0.043$. Twotailed Student's $t$-test was used to determine the statistical significance of data plotted in a. Two-way ANOVA followed by Bonferroni multiple comparisons test was used to analyze data from $\mathbf{b}$ and $\mathbf{c}$. One-way ANOVA followed by Tukey's Multiple Comparison test was used to analyze data from $\mathbf{d}$ and $\mathbf{e}$. ${ }^{\star} p<0.05,{ }^{\star \star} p<0.01,{ }^{\star \star \star} p<0.001$, n.s. not significant. Scale bar $50 \mu \mathrm{m}$.

demyelination when compared with vehicle-treated G93A mice (Supplementary Fig. 9a-d). Parallel sections, labelled for myelin basic protein (MBP) and medium neurofilaments (NF-M), showed deranged myelin in vehicle-treated G93A mice while compound 2a treatment preserved the integrity of myelin in G93A mice (Supplementary Fig. 9e).

Cell-secreted SOD1G93A in the extracellular space activates microglia by interaction with $\mathrm{CD} 14^{41,42}$. Therefore, we analyzed microglia/macrophages in SCs scoring $\mathrm{Iba}^{+}$cells and measured CD14 expression levels in G93A mice. Neither CD14 levels nor the total number of $\mathrm{Iba1}^{+}$cells changed in compound 2a-treated G93A mice when compared with vehicle-treated mice (Supplementary Fig. 10a-c). Our finding supports earlier reports of a rescue of behavioral deficits and pathological outcomes in $3 \mathrm{XTg}$ $\mathrm{AD}$ mice treated with an AAV-VPS35 vector, without functional alterations of the microglia/macrophage cell population ${ }^{43,44}$.

Compound 2a increases VPS35/VPS26 levels in G93A mice. Standard R55/1 increases VPS35 and VPS26 levels, and retromer functionality in cultured cells ${ }^{20}$. We asked whether compound 2a could do the same in G93A MNs, using confocal microscopy to quantify VPS35 fluorescence levels in MNs gated in the ventral horn of lumbar SCs. We observed a significant reduction of VPS35 mean fluorescence intensity (MFI) levels in vehicle-treated G93A mice. In contrast, treatment with compound 2a significantly increased such levels in MNs of G93A mice (Fig. 6a). We next assayed VPS26 MFI levels on parallel sections. As expected, MFI levels were reduced in vehicle-treated G93A mice, while they were significantly increased in compound 2a-treated mice (Fig. 6b). WBs of lumbar SC extracts confirmed the ability of 2a to increase VPS35 and VPS26b levels in G93A mice (Supplementary Fig. 11a, b).

We next asked whether increasing VPS35/26 protein levels is sufficient to increase retromer functionality. CI-MPR is unstable in VPS26-knockout cells ${ }^{21}$, and we observed a substantial reduction of CI-MPR MFI levels in MNs of vehicle-treated G93A mice compared with WT litters (Fig. 6c). However, MFI levels significantly increased in compound 2a-treated G93A MNs (Fig. 6c). Sortilin encodes a receptor belonging to the Vps10 family involved in Frontotemporal Dementia (FTD ${ }^{45}$, which shares functional homologies with MPRs and is another retromer cargo $^{46}$. Sortilin MFI levels were significantly reduced in MNs of vehicle-treated G93A mice, while significantly increased by compound 2a (Fig. 6d). 
a

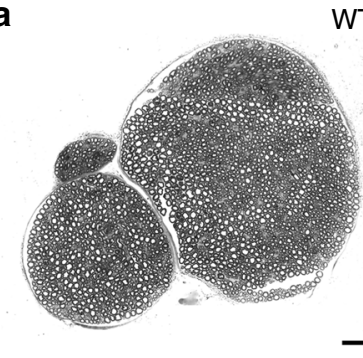

C

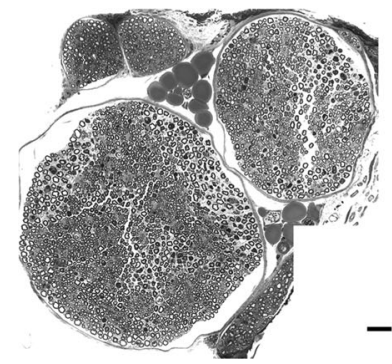

WT-vehicle

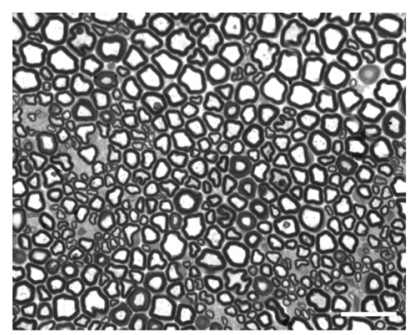

b

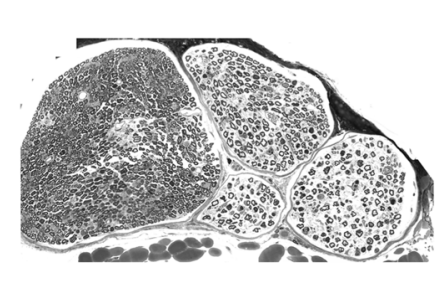

G93A-vehicle

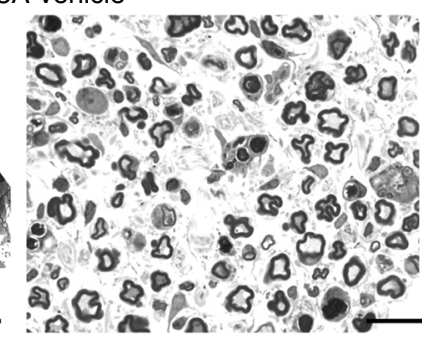

d

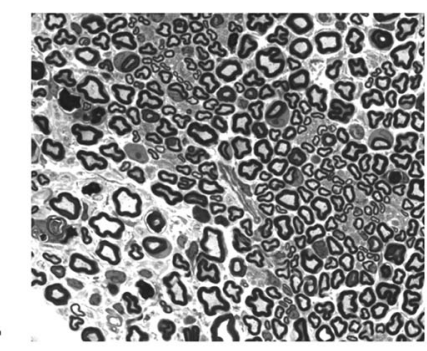

G93A-2a (10 mg/kg)
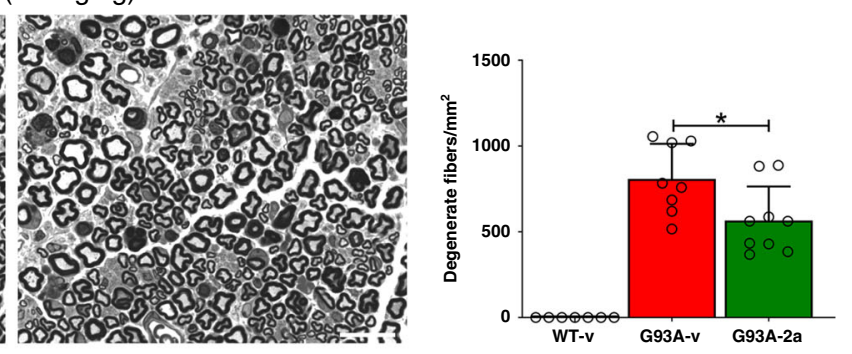

Fig. 5 Compound 2a attenuates sciatic nerve degeneration in G93A mice. a Low and high magnifications of a sciatic nerve cross section from a vehicletreated WT mouse. $\mathbf{b}$ Low and high magnifications of a sciatic nerve cross section from a vehicle-treated G93A mouse. c Low and high magnifications of a sciatic nerve cross section from a compound $\mathbf{2 a}(10 \mathrm{mg} / \mathrm{kg}$ )-treated G93A mouse (day 100). Quantifications (means + SD) of degenerating fibers/mm scored in the entire cross section of nerves are shown in $\mathbf{d}$, and data are examined over two independent experiments (WT $n=7$ independent mice, G93Avehicle $n=8$ independent mice, G93A-compound 2a $n=9$ independent mice).(G93A-v vs. G93A-2a: $p=0.02$. One-way ANOVA followed by Tukey's Multiple Comparison test was used to analyze data. ${ }^{\star} p<0.05$. Scale bars $50 \mu \mathrm{m}$ for low-magnification images and $20 \mu \mathrm{m}$ for high-magnification images.

We next investigated Cathepsin D (CTSD) expression and distribution in G93A mice, since its trafficking involves the retromer complex ${ }^{21}$. In humans, CTSD maturation starts with a pre-pro-CTSD then converted to pro-CTSD $(52 \mathrm{kDa})$ in the endoplasmic reticulum. Recycling of pro-CTSD and its downstream migration to acidic compartments involves CI-MPR and the retromer pathway ${ }^{21}$. Pro-CTSD is further processed to an intermediate form in late endosomes $(48 \mathrm{kDa})$, and finally converted to mature CTSD $(34 \mathrm{kDa})$ in lysosomes ${ }^{47}$. VPS35 inactivation $^{48}$ or VPS26 knockdown ${ }^{21}$ affect CTSD maturation. We scored CTSD levels in lumbar SC extracts from vehicletreated WT and vehicle- or 2a-treated G93A mice. We observed a slight, but not significant reduction of the mature CTSD/proCTSD ratio in SC extracts of vehicle-treated G93A mice compared with WT litters. Possibly, we did not see a reduction of mature CTSD in total protein lysates because glial cells of G93A mice express high amounts of mature CTSD at day $100^{7}$ (Fig. 6e). However, levels of mature CTSD significantly increased in compound 2a-treated G93A mice (Fig. 6e). We next analyzed CTSD levels and $\mathrm{CTSD}^{+}$puncta in MNs by confocal microscopy, observing their significant reduction in MNs of vehicle-treated G93A mice that was restored by treatment with compound 2a (Fig. 6f). These data suggest that retromer stabilization mediated by compound $\mathbf{2 a}$ restores Sortilin and CI-MPR expression levels in ALS mice and improves CTSD maturation, thus restoring lysosome health in ALS mice ${ }^{7,49}$.

Compound 2a increases lysosomal homeostasis in G93A mice. Ubiquitinated inclusions accumulate in MNs from sALS and fALS patients ${ }^{50}$, and in ALS mice ${ }^{51}$. We characterized polyubiquitinated proteins in lumbar SCs protein extracts by $10 \%$ denaturating PAGE. Protein extracts from Neuro2a cells treated with the proteasome inhibitor Bortezomib (BTZ), able to increase poly-ubiquitination, were used as an experimental control ${ }^{52}$ (Fig. 7a). Vehicle-treated G93A mice displayed abundant polyubiquitinated proteins whereas their levels were substantially reduced by compound 2a (Fig. 7b). We next scored ubiquitin MFI levels in ventral horn MNs of G93A mice. MFI levels of ubiquitin fluorescence in vehicle-treated G93A MNs were higher than in compound 2a-treated G93A mice, further confirming previous results $^{53}$ (Fig. $7 \mathrm{c}$ and $\mathrm{d}$ ). We next scored the Golgi apparatus in G93A mice by labeling lumbar sections for the cis-Golgi matrix protein GM13054. We observed that many MNs from vehicletreated G93A mice displayed a reduction of GM130-covered areas, possibly indicating the organelle fragmentation ${ }^{55}$ (Fig. 7e). However, this phenomenon was substantially reverted when we scored MNs of compound 2a-treated G93A mice (Fig. 7e).

Lysosomal alterations are early events in ALS,56. We speculated that an impairment of the retromer should alter protease trafficking via CI-MPR, and therefore disrupt lysosomal homeostasis $^{57}$. We determined whether a reduction of VPS35 levels in Neuro2a cells could affect lysosomal homeostasis, mimicking what was observed in ALS models ${ }^{7,56}$. We transfected Neuro2a cells with plasmids encoding the Sh56-RNAi to downregulate VPS35. After $24 \mathrm{~h}$ of starvation, we analyzed the lysosomes using Lyso-tracker ${ }^{58}$. We observed enlarged and abnormally distributed lysosomes in cells with VPS35 interference by Sh56 (Supplementary Fig. 12a-c). We next assessed that poly-ubiquitinated protein levels were doubled in Neuro2a cells receiving a VPS35-targeted RNAi, suggesting that loss of retromer functionality alters lysosomal homeostasis and the accumulation of poly-ubiquitinated proteins (Supplementary Fig. $12 \mathrm{~d}, \mathrm{e})^{21}$. We asked whether the overexpression of SOD1 ${ }^{\mathrm{G} 93 \mathrm{~A}}$ would also result in similar lysosomal alterations by transfecting Neuro2a cells with plasmids encoding SOD1G93A, with or without compound 2a. After $24 \mathrm{~h}$ of starvation, cells receiving only SOD1 ${ }^{\mathrm{G} 93 \mathrm{~A}}$ plasmids showed enlarged lysosomes, while as expected treatment with compound $\mathbf{2 a}$ significantly reverted this phenotype (Supplementary Fig. 12f, g).

Compound 2a counteracts SOD1G93A proteins aggregation. SOD1 mutations increase its propensity to aggregate in cells ${ }^{59}$. 

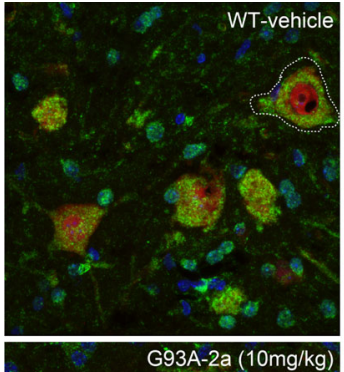

cosa-2a (10mg/k
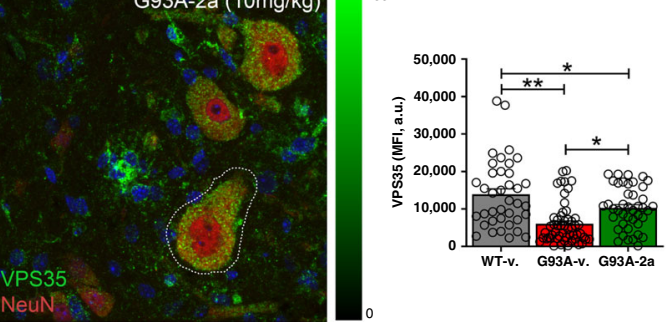

C
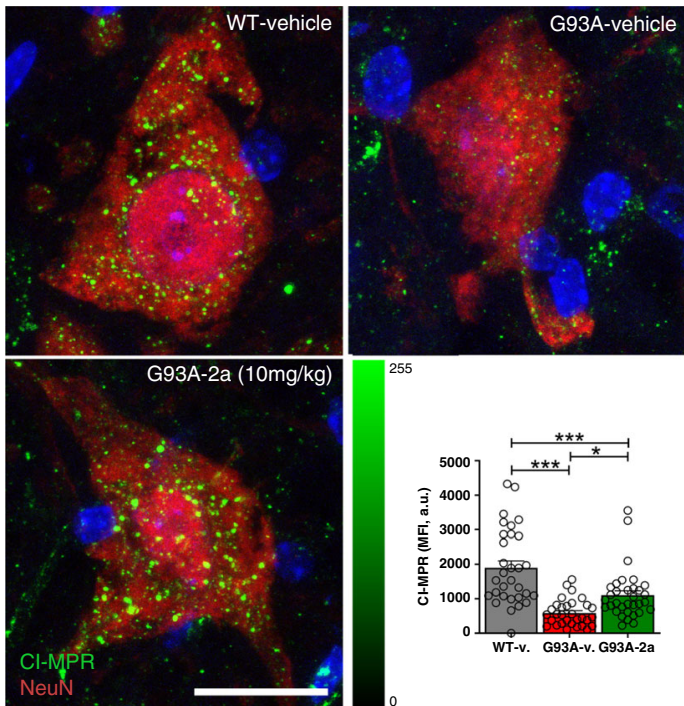

e

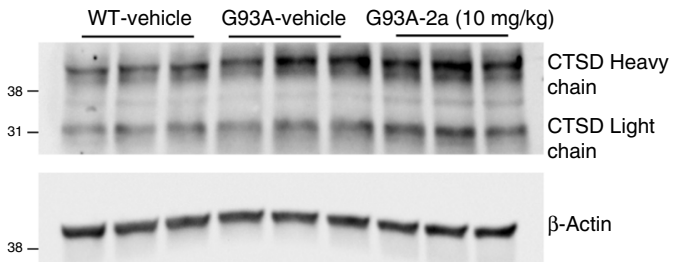

b
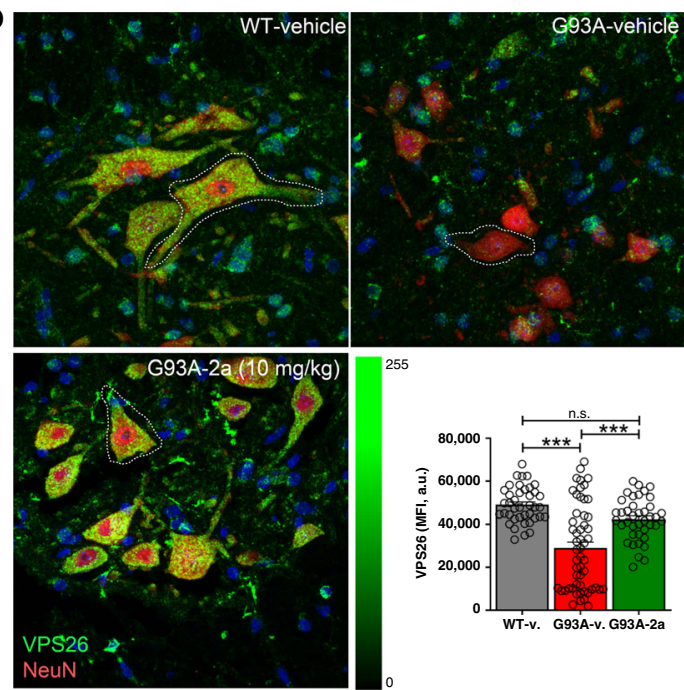

d

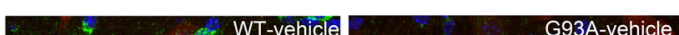

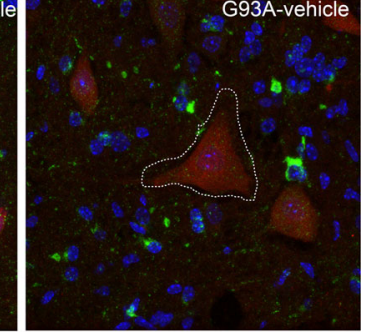
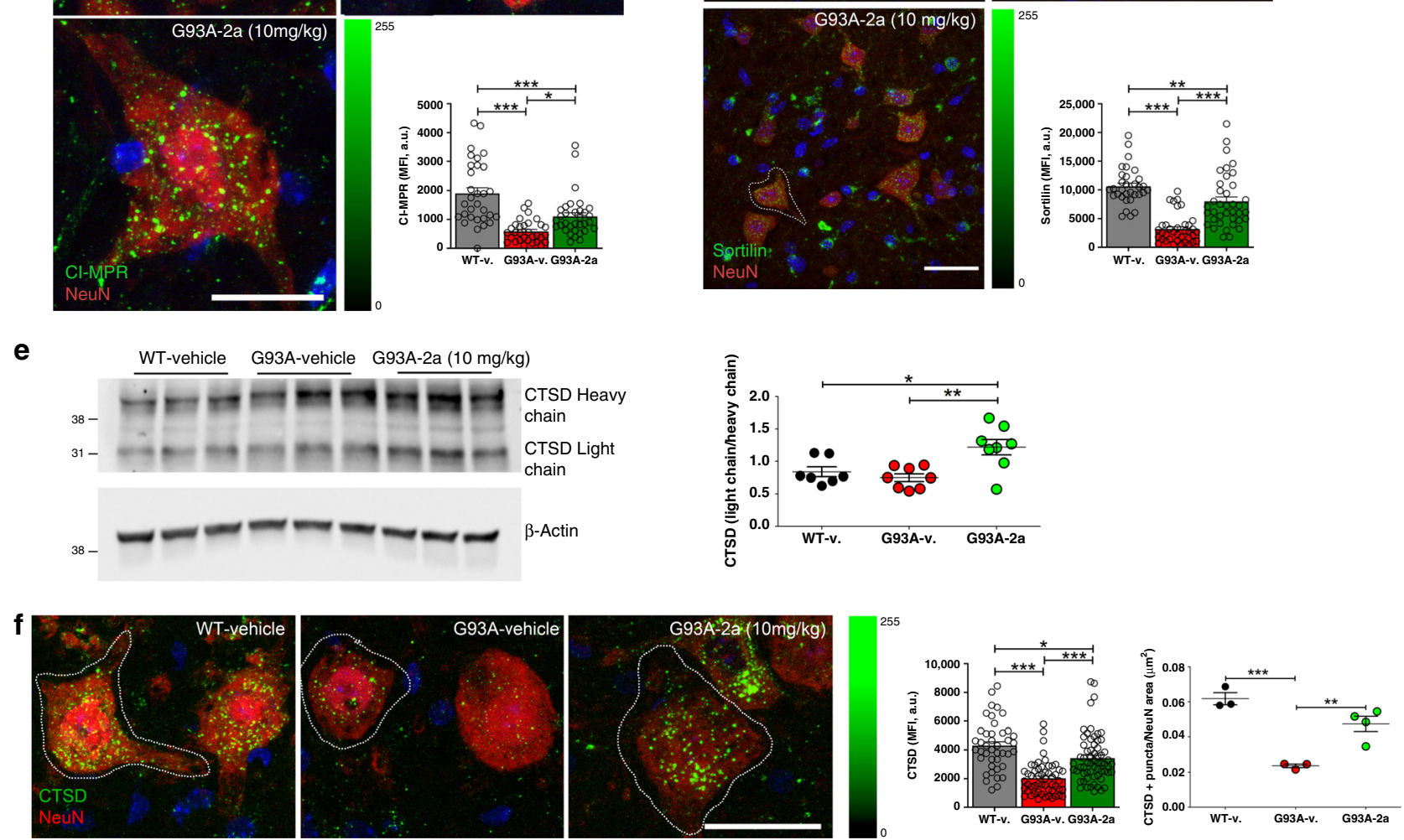

We checked whether compound 2a could reduce the accumulation of SOD1 $193 \mathrm{~A}$ aggregates in vivo. Starting at postnatal day 83 , we injected G93A mice and WT littermates daily with compound 2a. We scored motor performances in vehicle- and compound 2a-treated G93A mice until day 103. As expected, mice receiving compound 2a displayed a general attenuation of motor deficits (Supplementary Fig. 13a). We resolved SC protein extracts by blue-native polyacrylamide gel electrophoresis ${ }^{60}$, and probing them with anti-SOD1 antibodies we observed high molecular weight smears in G93A mice that were absent in WT litters. The intensity of such high MW entities was lowered in G93A mice treated with compound 2a (Supplementary Fig. 13b, c). These results suggest that retromer stabilization mediated by compound $\mathbf{2 a}$ increases lysosomal homeostasis in vitro 
Fig. 6 Compound 2a increases retromer proteins in G93A mice. (a-d, $\mathbf{f}$ ) maximum projections of confocal stacks from lumbar SCs (ventral horn) of vehicle-treated WT, vehicle-treated G93A and compound $2 a(10 \mathrm{mg} / \mathrm{kg}$, day 100)-treated G93A mice $(n=3$ independent mice/group) labelled for: VPS35/NeuN (a), VPS26/NeuN (b), CI-MPR/NeuN (c), Sortilin/NeuN (d), and CTSD/NeuN (f). Averaged fluorescence intensities (MFI) in gated NeuN ${ }^{+}$ MNs (WT-v: $n=38$ independent MNs, G93A-v: $n=54$ independent MNs, G93A-2a: $n=42$ independent MNs, data were examined from three independent experiments), of VPS35 (Alexafluor 488) are reported as mean arbitrary units (a.u. \pm SEM) in Panel a (WT-v vs. G93A-v $p=0.002$, WT-v vs. G93A-2a $p=0.046$, G93A-v vs. G93A-2a $p=0.011$ ). Averaged MFI (a.u. \pm SEM) of VPS26 (Alexafluor 488) quantified in gated NeuN+ MNs (WT-v: $n=$ 40 independent MNs, G93A-v: $n=54$ independent MNs, G93A-2a: $n=40$ independent MNs, data are examined from three independent experiments) are shown in $\mathbf{b}$ (G93A-v vs. G93A-2a $p=0.09$, other comparisons $p<0.0001$ ). Averaged MFI of Cl-MPR (Alexafluor 488, a.u. \pm SEM) in NeuN ${ }^{+}$MNs (WT-v: $n=31$ independent MNs, G93A-v: $n=31$ independent MNs, G93A-2a: $n=33$ independent MNs, data are examined from three independent experiments) are shown in c (G93A-v vs. G93A-2a $p=0.026$, other comparisons $p<0.0001$ ). Averaged Sortilin MFI levels (Alexafluor 488 a.u. \pm SEM) quantified in gated NeuN ${ }^{+}$MNs (WT-v: $n=33$ independent MNs, G93A-v: $n=37$ independent MNs, G93A-2a: $n=38$ independent MNs, data are examined from three independent experiments) are shown in $\mathbf{d}$. Epi-fluorescence scales are shown on the right side of a-d (WT-v vs. G93A-2a $p=0.009$, other comparisons $p<0.0001$ ). e Representative WB for CTSD (heavy (46-50 KDa) and light (28-30 KDa chains). Normalization of proteins load was done by $\beta$-Actin. The histogram in e shows quantifications (WT-v: $n=7$ independent mice, G93A-v: $n=8$ independent mice, G93A-2a: $n=8$ independent mice, data are examined from two independent experiments; lines show mean + SEM). WT-v vs. G93A-2a $p=0.02$, G93A-v vs. G93A-2a $p=0.0032$. f Averaged CTSD MFI levels (Alexafluor 488, a.u. \pm SEM) in gated NeuN+ MNs (WT-v: $n=42$ independent MNs, G93A-v: $n=54$ independent MNs, G93A-2a: $n=63$ independent MNs, data are examined from three independent experiments). The epi-fluorescence scale is shown in $\mathbf{f}$ (WT-v vs. G93A-2a $p=0.011$, other comparisons $p<0.0001$ ). Numbers of CTSD puncta normalized for the area of $\mathrm{NeuN}^{+}$MNs are shown in the histogram (WT-v: $n=3$ independent mice, G93A-v: $n=3$ independent mice, G93A-2a: $n=4$ independent mice, data are examined from two independent experiments, lines show mean + SEM). (WT-v vs. G93A-v $p=0.0005$, G93A-v vs. G93A-2a $p=0.006$. One-way ANOVA followed by Tukey's Multiple Comparison test was used to analyze data in a-f. ${ }^{\star} p<0.05,{ }^{\star \star} p<0.01,{ }^{\star \star \star} p<0.001$. Scale bars $30 \mu \mathrm{m}$ for $\mathbf{a}, \mathbf{b}, \mathbf{d}$, and $\mathbf{f} ; 25 \mu \mathrm{m}$ for $\mathbf{c}$.

and in vivo, decreases protein polyubiquitination and diminishes G93A aggregation.

VPS35 expression in ASL SCs and in iPSCs-derived MNs from ALS fibroblasts. We investigated VPS35 expression in human MNs located in the ventral horn of the SC (Fig. 8a). VPS35 immunoreactivity was substantially reduced in ALS MNs, confirming our observations in G93A mice (Fig. 8b). Parallel sections probed for VPS26 revealed a substantial reduction of VPS26 immunoreactivity in ALS samples (Fig. 8c, d).

We next generated iPSC lines from fibroblasts obtained from fALS patients carrying three SOD1 gene variants (ALS 8: p. Asn65Ser; ALS 13: p.Leu144Phe; ALS 27: p.Asp97Asn), and from three healthy volunteers. Efficient reprogramming was assessed by labelling cultures for OCT3/4, SOX2, NANOG, TRA1-60, and SSEA4 (Supplementary Fig. 14). We observed a normal karyotype in ALS cell lines (Supplementary Fig. 15a). According to literature ${ }^{61}$ we induced the phenotype of caudal neuroepithelial $\mathrm{OLIG}^{+}{ }^{+} \mathrm{PAX}_{6}{ }^{-}$progenitors in iPSCs (Supplementary Fig. 15b, c), and we differentiated them to acquire the OLIG2-ISLET1 ${ }^{+}$cell phenotype. We scored the ISLET1 ${ }^{+}$percentage among nuclei, observing similar rates of cell differentiation among controls and ALS cells (controls: $81.6 \% \pm 9$; ALS: $81.8 \% \pm 12$, Supplementary Fig. 15d, e). Using immunofluorescence and WBs, we observed that VPS35 levels in ISLET1 ${ }^{+}$MNs were reduced in ALS samples (Fig. 8e, f). We next selected a control cell line (\#8) and an ALS cell line (ALS 27) for compound 2a treatment. After establishing $\mathrm{OLIG}^{+}{ }^{+} \mathrm{PAX}_{6}{ }^{-}$progenitors, we differentiated these cells in presence of compound $2 \mathrm{a}(10 \mu \mathrm{M}, 6$ days). Cells were labelled for ISLET1 and VPS35 and by confocal microscopy, and we scored VPS35 ${ }^{+}$puncta. ALS 27 cells displayed less VPS35 ${ }^{+}$ puncta than controls, albeit both cell types significantly increased

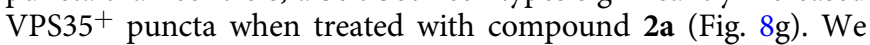
next used WB for o confirm the ability of compound $2 a$ to increase VPS35 protein levels in ALS cells (Fig. 8h). Altogether, these results suggest that compound $\mathbf{2 a}$ can be used to stabilize the retromer complex in ALS models.

\section{Discussion}

We describe a substantial reduction of CRC proteins in MNs of G93A mice. Similarly, we observe a reduction of VPS35 levels in MNs scored in postmortem ALS patients, and in human iPSC- derived MNs from fALS patients. As retromer failures occur in $\mathrm{AD}^{62}$ and $\mathrm{PD}^{17}$ neurons, we speculate that the reduction of retromer levels observed in ALS represents one among many aberrant responses and deficits that affect neurons overwhelmed by misfolded/aggregated proteins.

This alteration occurs early in G93A mice, suggesting that the retromer could be an early therapeutic target in ALS, albeit future investigations are needed to identify mechanisms leading to retromer failure in ALS MNs.

The CRC core element of the retromer and the SNX dimer assemble to create a functional retromer complex ${ }^{8,22,61}$. Knockdown of a single CRC protein affects the expression of the other CRC members ${ }^{15,21}$. On the other hand, strengthening the interaction between proteins assembled in the CRC bolsters full retromer stability, and increases its functionality as elegantly described $^{20}$.

Compounds binding to the interface between VPS35 and VPS29 and stabilizing the retromer assembly were identified by virtual screening. Among them, bis-isothiourea R55/1 increased VPS35 levels ( $\sim 60 \%)$ in cells, and therefore the general stability of the retromer complex ${ }^{20}$. Treatment of neurons carrying pathogenic APP mutations with R55/1 reduced the accumulation of amyloid- $\beta$ (A $\beta)$ peptides as well as APP processing ${ }^{20}$.

We designed and synthesized a small array of phenyl bisguanylhydrazone chaperones that interact with the CRC complex at the VPS35-VPS29 interface, as R55/1. We selected compound 2a, due to its ability to increase VPS35 levels in Neuro2a cells and to cross the BBB. Through STD-NMR and WL-NMR experiments we experimentally proved the binding of 2a to the VPS29VPS35 heterodimer.

We assayed compound $\mathbf{2 a}$ in vitro by overexpressing SOD1 ${ }^{\mathrm{G} 93 \mathrm{~A}}$ in cells. The overexpression of mutant SOD1 increases rates of cell death in MN-like NSC-34 cells ${ }^{5}$, and SOD1G93A affects Neuro2a cell survival ${ }^{63}$. Compound 2a significantly counteracted cell death and reduced LDH release in Neuro2a cells transfected with SOD1 ${ }^{\mathrm{G} 93 \mathrm{~A}}$ plasmids. Although we cannot rule out the possibility that compound 2 a modulates additional targets other than the CRC, we observed that it failed to rescue Neuro2a cell survival and to inhibit LDH release in presence of VPS35targeted siRNA.

We used compound $\mathbf{2 a}$ to restore retromer levels in G93A mice. Transgenic mice and their WT litters well tolerated 
a

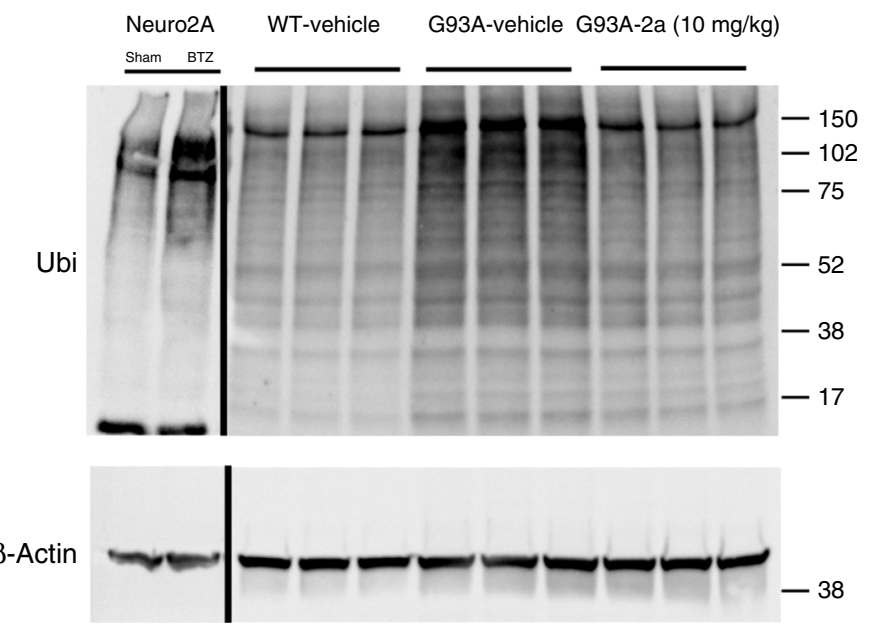

c
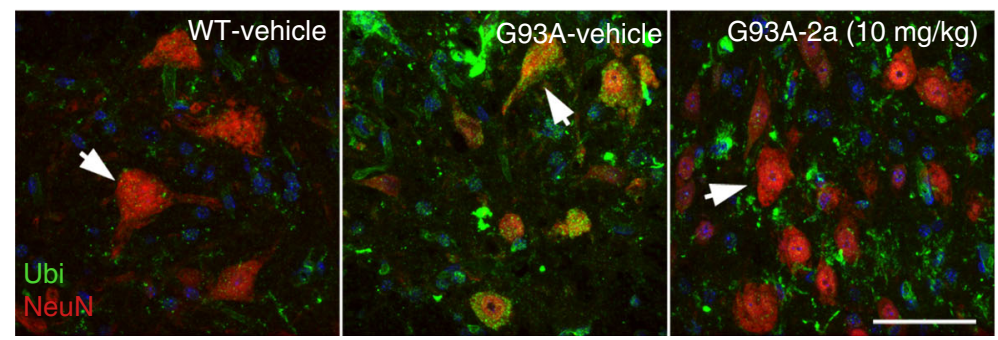

b
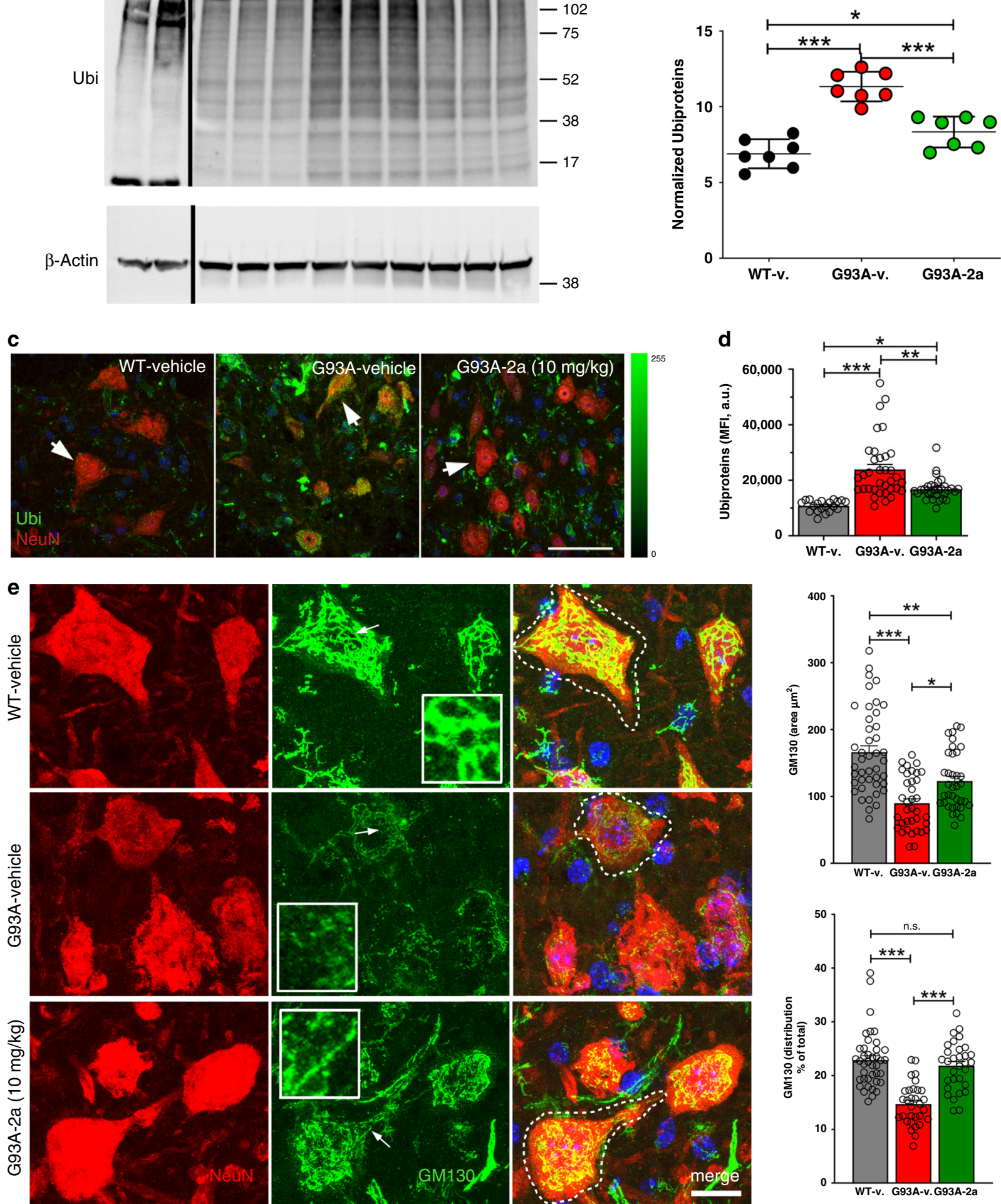
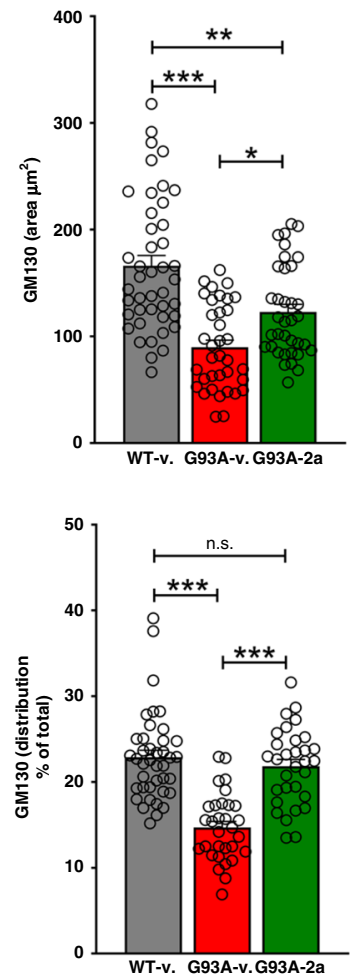

intraperitoneally delivered compound $\mathbf{2 a}$, as we did not observe distress, aberrant behavior or pain in treated mice. This in vivo observation is coherent with in vitro low toxicity of compound 2a, and with the absence of toxic effects in mice expressing AAVVPS $35^{43}$.

Neurons cannot divide, and therefore cannot dilute cytoplasmic misfolded/aggregated proteins that accumulate. Their removal is a complex task involving recognition proteins, chaperones, and eventually activation of degradation pathways such as the ubiquitin-proteasome system and the autophagy-lysosomal pathway 64 , both altered in ALS. Mutant SOD1 proteins associate with reduced expression of components of the ubiquitinproteasome system ${ }^{65}$. C9orf72, an ALS causative gene, is a regulator of autophagy ${ }^{66}$ and a keeper of lysosome homeostasis ${ }^{67}$. 
Fig. 7 Compound 2a reduces protein ubiquitination in G93A mice. a Representative WB for poly-ubiquitinated proteins in experimental controls: Neuro2a cells $\left(3 \times 10^{5}\right.$ cells/well) treated with sham or with Bortezomib (10 $\left.\mathrm{nM}, \mathrm{BTZ}\right)$; and in lumbar SC extracts from vehicle-treated WT mice, vehicle-treated G93A mice and compound 2a-treated G93A mice (10 mg/kg, day 100). Normalization of proteins load was done by $\beta$-Actin. Dividing black lines show lanes cropped from independent filters. b Collective densities of lanes, normalized for $\beta$-Actin, were used for quantification ( $n=7$ independent mice/group data are examined from three independent experiments, lines show means + SD). WT-v vs G93A-2a: $p=0.013, p<0.0001$ for the other comparisons. c Maximum projections of confocal stacks from lumbar SCs sections of vehicle-treated WT, vehicle-treated G93A and compound 2a-treated G93A mice $(10 \mathrm{mg} / \mathrm{kg}$, sampled at day 100) labelled for ubiquitin (Ubi) and NeuN ( $n=3$ independent mice/group). Averaged fluorescence intensities (MFI, lines show means + SEM) in gated Neun ${ }^{+}$MNs of Ubi (Alexafluor 488) are reported in $\mathbf{d}$ (arrows indicate representative cells; WT-v: $n=20$ independent MNs, G93A-v: $n=35$ independent MNs, G93A-2a: $n=31$ independent MNs, data are examined from three independent experiments; WT-v vs. G93A-2a: $p=$ $0.014, p<0.0001$ for the other comparisons). The epi-fluorescence scale is shown in right side. e Maximum projections of confocal stacks (step of $0.4 \mu \mathrm{m}$ ) of MNs labelled for NeuN and GM130. Arrows in each panel indicate regions showed at high magnification in insets. Quantifications (means \pm SEM) of GM130 area are shown in upper $\mathbf{e}$, (WT-v: $n=43$ independent MNs, G93A-v: $n=36$ independent MNs, G93A-2a: $n=36$ independent MNs, data are examined from three independent experiments; G93A-v vs. G93A-2a: $p=0.0018 ; p<0.0001$ for the other comparisons). Quantifications of GM130 distribution (mean\% of the cell area \pm SEM) are shown in lower panel e, (WT-v: $n=40$ independent MNs, G93A-v: $n=31$ independent MNs, G93A-2a: $n=31$ independent MNs, data are examined from three independent experiments; WT-v vs. G93A-2a: $p=0.63, p<0.0001$ for the other comparisons). One-way ANOVA followed by Tukey's Multiple Comparison test was used to analyze data of $\mathbf{b}-\mathbf{e} .{ }^{\star} p<0.05,{ }^{\star \star} p<0.01,{ }^{\star \star \star} p<0.001$, n.s. not significant. Scale bar $50 \mu \mathrm{m}$ in $\mathbf{c}$ and $20 \mu \mathrm{m}$ in $\mathbf{e}$.

Lysosomal deficits are well documented in G93A mice and starting from day 40 , the levels of CTSD are significantly reduced in $\mathrm{MNs}^{7}$ from these mice. The maturation of this lysosomal enzyme involves CI-MPR and a functional retromer ${ }^{21}$. We observed increased levels of both CI-MPR and CTSD in MNs of G93A mice treated with compound 2a. Therefore, we hypothesized that increasing retromer stabilization could increase the delivery of CTSD to the lysosomal compartment and finally the lysosomal functionality. These data are far from conclusive, and further experiments aimed to inactivate CTSD in G93A mice are needed to investigate its contribution to the degradation of misfolded proteins.

Golgi fragmentation is commonly observed in MNs of sALS and fALS patients ${ }^{35,68}$. Using compound $\mathbf{2 a}$ we observed a substantial attenuation of Golgi fragmentation in SOD1G93A overexpressing cells and in G93A mice. The mechanism(s) that connect retromer stabilization to the rescue of Golgi fragmentation are unknown, although experimental evidence suggests a functional link between a protein belonging to Vesicle Associated Membrane Protein (VAMP)-associated proteins (VAP) VPSs and Golgi homeostasis. A mutant form of $V A P-B$ (P56S) was described in a family of ALS patients ${ }^{69}$, and VAP-B levels are dampened in $\mathrm{MNs}$ of $\mathrm{G} 93 \mathrm{~A}$ mice ${ }^{70}$. The retromer complex interacts with VAP-B and such interaction occurs in regions in which the ER makes contacts with endosomes ${ }^{71}$. It is tempting to speculate that increasing the retromer stability with compound 2a, we can also restore VAP-B functionality, indirectly restoring homeostasis. Further investigations will help to dissect the interaction between VAPs and retromer in ALS mice.

Compound 2a attenuated locomotion impairment in G93A mice, and significantly increased the number of surviving MNs. These functional effects correlate with the ability of 2a to increase CRC protein levels in MNs, but further experiments with VPS35 conditional $\mathrm{KO}$ mice will further validate in vivo the mechanism of action of compound $2 \mathrm{a}$.

Lysosomal alterations probably concur to increase the accumulation of poly-ubiquitinated proteins in the lumbar SC ${ }^{72}$. Such pathological phenomenon was significantly reduced in vitro and in vivo by compound 2a. We do not know whether retromer failure is the leading trigger inducing the loss of lysosomal functionality in ALS, but we observed that either VPS35 knockdown or overexpression of SOD1G93A in Neuro2a cells increased poly-ubiquitinated protein levels. We acknowledge that failure of the retromer complex could lead to lysosomal deficits, autophagy alteration and exaggerated protein poly-ubiquitination by synergizing with other detrimental pathways operating in the ALS pathophysiology. Similarly, G93A mice receiving compound 2adriven retromer stabilization showed a substantial reduction of high molecular weight SOD1 aggregates.

Therefore, pharmacological retromer stabilizers could be useful to delay degenerative processes occurring in ALS.

\section{Methods \\ Docking experiments. The docking analysis was performed with} AutoDock4.2 software ${ }^{73}$ building the coordinates of the VPS29-VPS35 heterodimer $^{74}$ (pdb-id 2r17). Each ligand was drawn with the program "Marvin Sketch v20.13.0" (Chemaxon packages; https://chemaxon.com/), converted in a 3D structure and then transformed in the pdbqt format with the addition of partial charges and rotatable bonds (http://mgltools.scripps.edu). A cubic docking grid centered around the side chain of Gln530 of VPS35 with $15 \AA$ side length was used for explorations. We performed 40 independent, global-local Lamarkian geneticalgorithm runs for each tested compound, extracting the conformation, the binding energy and the calculated $\mathrm{Kd}$ of the best pose together with the number of poses clustered around such best conformation (Python Molecular Viewer http:// mgltools.scripps.edu). Additionally, we utilized a sigmoidal rectification function shown in Supplementary Fig. 4a to weight the calculated Kd with recurrence of best docking poses and generate a normalized $\mathrm{Kd}$, as explained in the main text.

Druggability parameters. $\mathrm{pKa}$ and $\operatorname{cog} \mathrm{P}$ values were calculated using the "Calculator Plugins" module of the ChemAxon's Marvin suite (https://chemaxon.com/ marvin-archive). We used the default parameters without any correction.

Synthesis. General procedures: ${ }^{1} \mathrm{H}-\mathrm{NMR}$ spectra were recorded on a Bruker Avance $400 \mathrm{MHz}$ instrument in $\mathrm{CDCl}_{3}, \mathrm{CD}_{3} \mathrm{OD}$, or $\mathrm{D}_{2} \mathrm{O}$ as solvent at $400 \mathrm{MHz}$ ${ }^{13} \mathrm{C}-\mathrm{NMR}$ spectra were recorded in $\mathrm{CDCl}_{3}, \mathrm{CD}_{3} \mathrm{OD}$, or $\mathrm{D}_{2} \mathrm{O}$ as solvent at $101 \mathrm{MHz}$ Coupling constants are expressed in Hertz and are rounded to the nearest $0.1 \mathrm{~Hz}$. LC-MS data were collected with a Waters Acquity ${ }^{\mathrm{TM}}$ Ultra performance LC equipped with an Acquity UPLC ${ }^{\mathrm{TM}}$ HSS T3 column $(2.1 \times 50 \mathrm{~mm}, 1.8 \mu \mathrm{m})$ and a SQD detector. Purifications were carried out either by flash chromatography on silica gel (particle size $60 \mu \mathrm{m}, 230-400$ mesh), on Kieselgel, or by Biotage ${ }^{\mathrm{TM}}$ flash chromatography [Biotage columns Si- $25-\mathrm{M}(150 \times 25 \mathrm{~mm}$; silica gel $(40-63 \mu \mathrm{m})$, flow rate $25 \mathrm{~mL} / \mathrm{min}$ )], or by Biotage ${ }^{\mathrm{TM}} \mathrm{C}_{18}$ reverse phase chromatography [Biotage column $\mathrm{C}_{18} \mathrm{HS}\left(150 \times 25 \mathrm{~mm}\right.$; KP-C ${ }_{18}$ - $\mathrm{HS}(35-70 \mu \mathrm{m})$, flow rate $\left.25 \mathrm{~mL} / \mathrm{min}\right)$ ] Some final compounds were purified by $\mathrm{C}_{18}$ reverse phase semi-preparative HPLC using a Waters X-Bridge column $(19 \mathrm{~mm} \times 15.0 \mathrm{~cm}, 5 \mu \mathrm{m})$. Melting points were determined with a Stuart Scientific SMP3 melting point apparatus. Solvents were distilled and dried according to standard procedures, and reactions requiring anhydrous conditions were performed under nitrogen or argon atmosphere.

Synthesis of bis-1,3-phenyl guanylhydrazone 2a. Compound 2a (280 mg, 0.88 mmoles, $88 \%$ yield, $\geq 95 \%$ purity, m.p. $200-202{ }^{\circ} \mathrm{C}$, white solid) was prepared in a single step from commercially available isophthalic aldehyde and aminoguanidine dihydrochloride. Diode Array LC trace, TIC trace and ES scan for compound 2a are available in Supplementary Fig. $4 \mathrm{e} ;{ }^{1} \mathrm{H}-\mathrm{NMR}$ and ${ }^{13} \mathrm{C}-\mathrm{NMR}$ are provided in the Supplementary Fig. 4f and g, respectively.

Animals and treatments. Mice were maintained under pathogen-free conditions at San Raffaele Hospital mouse facility (Milan, Italy). All efforts were made to minimize animal suffering and to reduce the number of mice used in accordance 

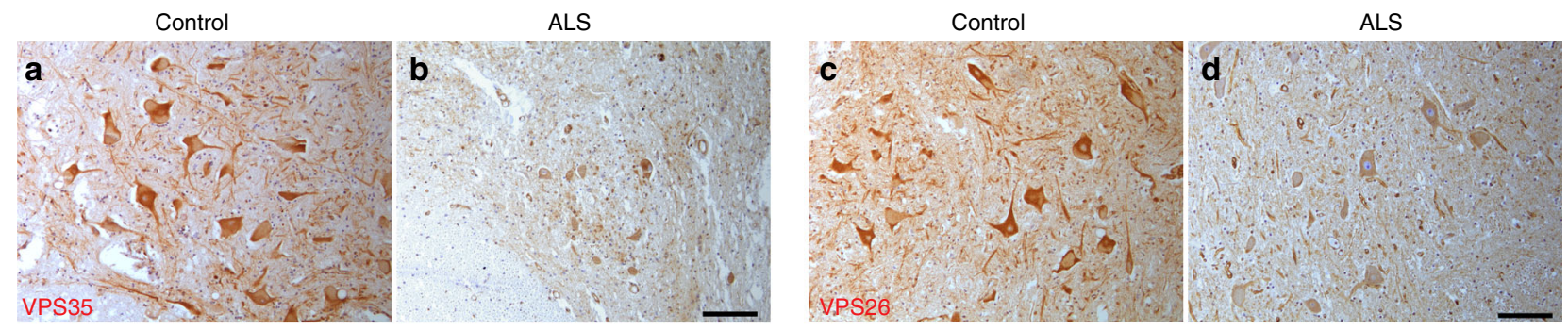

e
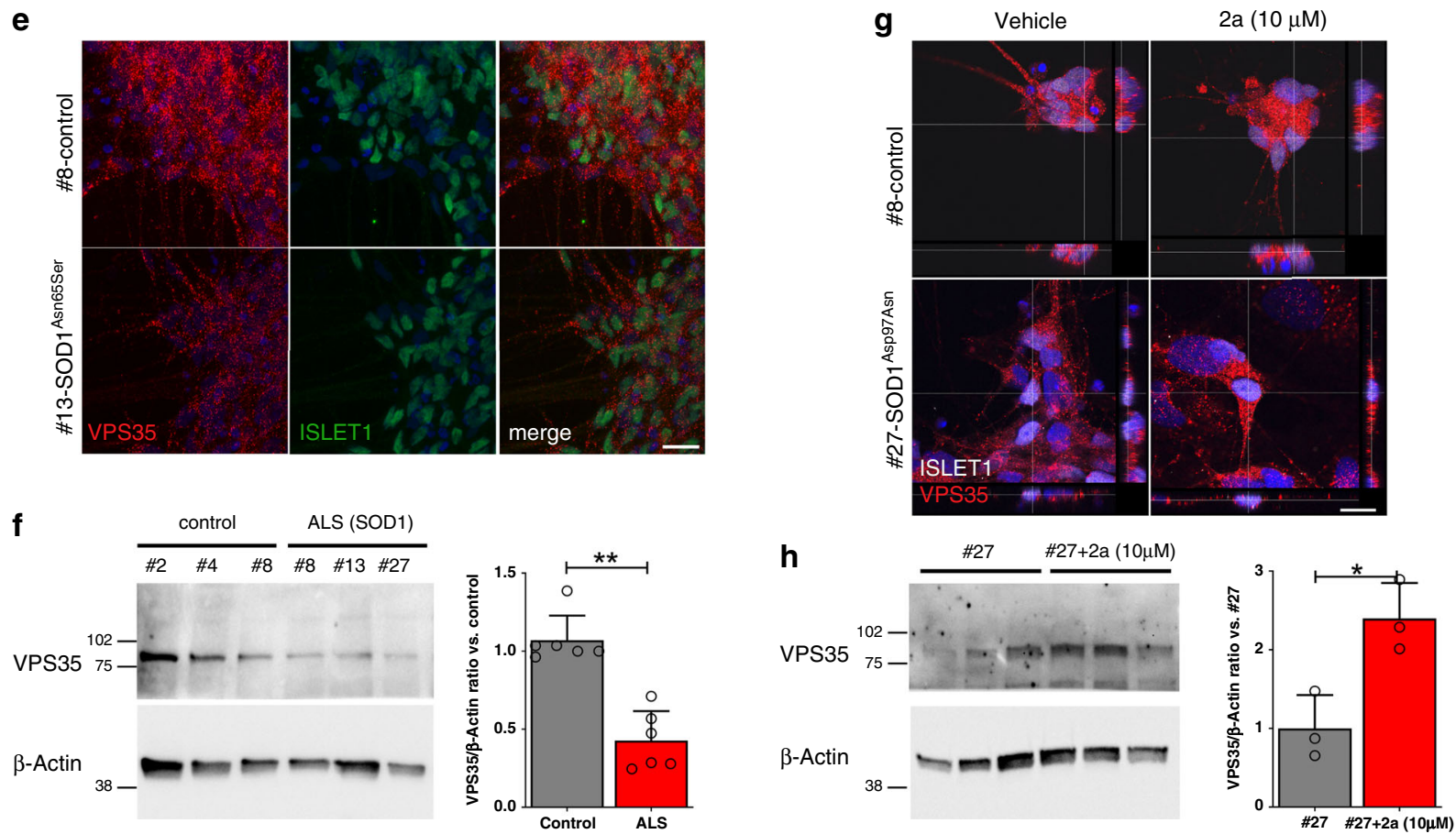

Fig. 8 VPS35 levels in ALS iPSCs-derived MNs and postmortem biopsies. a, b $1 H C$ for VPS35 in alpha-MNs in representative sections from ventral horns of SCs biopsies from a non-neurological control (a) and an ALS patient (b). c, d, IHC for VPS26 in alpha-MNs sampled in adjacent sections from a nonneurological control (c) and an ALS patient (d). Analyses were done on four non-neurological control biopsies and five ALS biopsies examined over three independent experiments. e Maximum projections of representative confocal stacks (three independent experiments) for VPS35 and ISLET1 in representative cultures of iPSC-derived MNs from a healthy volunteer (\#8) and an ALS patient (\#13SOD1Leu144Phe). A representative WB for VPS35 and $\beta$ Actin in protein extracts from iPSCs-derived MN cultures (\#8 SOD1Asn65Ser, \#13SOD1Leu144Phe, \#27 SOD1Asp97Asn and age- and sex-matched healthy volunteers \#2, \#4, and \#8) is shown in $\mathbf{f}$. Quantifications derived from $n=3$ controls (\#2, \#4, and \#8) and from $n=3$ ALS (\#8, \#13, and \#27), means $( \pm S D)$ are examined from two independent experiments $(p=0.005)$. $g$ Representative cross-sectional analysis of confocal stacks (three independent experiments) for VPS35 and ISLET1 in cultured iPSCs-derived MNs from an healthy volunteer (\#8) and from an ALS patient (\#27 SOD1Asp97Asn) with or without compound $\mathbf{2 a}(10 \mu \mathrm{M}$ for 6 days). h Representative WB for VPS35 and $\beta$-Actin in iPSCs-derived MNs of an ALS patient (\#27) treated with vehicle or with compound $\mathbf{2 a}$ (10 $\mu \mathrm{M}$ for 6 days). Quantifications (means $\pm \mathrm{SD}$ ) derived from $n=3$ wells/treatment and data are examined from one experiment $(p=0.017)$. Two-tailed Student's t-test was used to determine the statistical significance in $\mathbf{f}$ and $\mathbf{h}$. ${ }^{\star \star} p<0.01$. Scale bar: $150 \mu \mathrm{m}$ in $\mathbf{d}, 25 \mu \mathrm{m}$ in e, $15 \mu \mathrm{m}$ in $\mathbf{g}$

with the European Communities Council Directive of 24 November 1986 (86/609/ EEC). The Ethics Review Committee approved experimental protocols according guidelines from the Italian Ministry of Health and from the Institutional Animal Care and Use Committee of the San Raffaele Scientific Institute (protocol number 704/2015PR). Transgenic mutant SOD1 mice carrying the SOD1 ${ }^{\mathrm{G} 93 \mathrm{~A}}$ allele (strain B6SJL-TgN[SOD1G93A] 1 GUR ${ }^{75}$ were purchased from Jackson laboratories, while C57BL/6J mice, used for breeding and experimental purposes, were purchased from Charles River (Italy). Both transgenic and WT mice had food and water freely available in the home-cage. The holding room was on a 12-h light-dark cycle, the temperature of the room was $22 \pm 0.2^{\circ} \mathrm{C}$. Starting from day 30 we intraperitoneally injected compound $2 \mathrm{a}(10 \mathrm{mg} / \mathrm{Kg})$ or vehicle in G93A mice as well as in C57BL/6J mice for 70 days. Additional experiments were performed injecting mice from day 83 to day 103. An operator blind to the treatment performed injections and manipulation of mice. At the day of the sacrifice, mice received an overdose of anesthetic drugs and they were perfused via vascular system with saline followed by $70-80 \mathrm{ml} 4 \%$ paraformaldehyde (PF) in PBS, pH 7.2 (Sigma-Aldrich). Spinal cords were coronally sliced at $\sim 6$-mm thickness and postfixed in $4 \% \mathrm{PF}$ in PBS, $\mathrm{pH} 7.2$ for $12 \mathrm{~h}$ at $+4{ }^{\circ} \mathrm{C}$. Tissues were cryoprotected in PBS $1 \mathrm{X} / 30 \%$ Sucrose (Sigma-Aldrich), embedded in OCT inclusion media and stored at $-80^{\circ} \mathrm{C}$ before processing. Lumbar spinal cords were $12-\mu \mathrm{m}$ sectioned, labelled and digital images were acquired every $330 \mu \mathrm{m}$ in a region encompassing $2.4 \mathrm{~mm}$ of the lumbar spinal cord. We determined numbers of mice by preliminary results or literature precedent ${ }^{76}$.

Motor function. Motor activity of mice receiving compound $\mathbf{2 a}$ or vehicle was assessed on 50-, 60-, 70-, 80-, 90-, and 100-days-old animals. Briefly, mice were trained $1 \mathrm{~min}$ on a static rotor and $1 \mathrm{~min}$ at constant speed $(4 \mathrm{rpm})$ for two times and then we ran two trials performed over two consecutive days (one per day). Each trial consisted of 6-test sessions with 15 min interval between sessions. For each session, we placed mice on an accelerating rotor $(4-40 \mathrm{rpm})$ and the latency to fall was recorded, with a maximum limit for individual animal set at 600 seconds.

Mass spectrometry quantitative analysis of compound 2a. Quantification of compound 2a in CNS extracts of C57BL/6J mice was performed at ProMeFa facility (Proteomics and Metabolomics Facility) of San Raffaele Scientific Institute. Wild-type C57BL/6J males mice (P60) were intraperitoneally injected with compound $2 \mathbf{a}(10 \mathrm{mg} / \mathrm{kg})$ or vehicle, daily. We sacrificed mice at the following time points: $1,7,15$, and 30 days. Before brains collection, mice received saline perfusion. Brains were weighted $(\sim 350 \mathrm{mg}$ each $)$ and rapidly frozen at $-80^{\circ} \mathrm{C}$. The 
extraction was performed with methanol and each biological sample was resuspended in $60 \mu \mathrm{l}$ of LC/MS grade water and $5 \mu \mathrm{L}$ were analyzed by LC-MS/MS using the UPLC 1290 (Agilent Technologies) coupled to the TripleTOF 5600+ mass spectrometer (SCIEX). The mass spectrometry analysis was carried out in positive mode, in the range of $50-500 \mathrm{~m} / \mathrm{z}$ for both the TOF-MS scan and the product ion scan, with a selected product ion of 247.1. A Waters ACQUITY UPLC BEH HILIC column $(2.1 \times 10 \mathrm{~mm}, 1.7 \mu \mathrm{m})$ was used for the chromatographic separation through a gradient of solvent $\mathrm{A}$ (acetonitrile $+0.1 \%$ formic acid) and solvent $\mathrm{B}$ (water $+0.1 \%$ formic acid) from $2 \%$ up to $29 \%$ B in 5 minutes with a flow rate of $600 \mu \mathrm{l} / \mathrm{min}$. Calibration curve in brain was constructed by plotting the peak area versus corresponding quantities of compound $2 \mathrm{a}(0 ; 0.1 ; 0.26 ; 1 \mathrm{nmol}$, run in quadruplicates, $\mathrm{R} 2=0.9443$ ), using MultiQuant 2.1 software (SCIEX).

NMR spectroscopy. NMR spectra were acquired at $298 \mathrm{~K}$ on a Bruker Avance NEO $700 \mathrm{MHz}$ spectrometer equipped with a Z-gradient cryoprobe. The spectra were processed with the Bruker TOPSPIN 4.0.5 software packages. For NMR studies of compound 2a with VPS29-VPS35, $5 \mu$ from a DMSO- $\mathrm{d}_{6}$ stock $20 \mathrm{mM}$ solution were dissolved in $175 \mu \mathrm{l}$ of buffer $\left(50 \mathrm{mM} \mathrm{KH}_{2} \mathrm{PO}_{4}, 50 \mathrm{mM} \mathrm{Na}_{2} \mathrm{HPO}_{4}, \mathrm{pH}\right.$ $8.0,150 \mathrm{mM} \mathrm{NaCl}, 2 \mathrm{mM}$ DTT) and $20 \mu \mathrm{L}$ of ${ }^{2} \mathrm{H}_{2} \mathrm{O}$. Saturation Transfer Difference spectra $\left({ }^{1} \mathrm{H}\right.$ spectral window $=16 \mathrm{ppm}$; relaxation delay $=3.0 \mathrm{~s}$; number of points $=32 \mathrm{~K}$ ) were acquired with 1024 scans with on-resonance irradiation at $-1.0 \mathrm{ppm}$ for selective saturation of protein resonances, and off-resonance irradiation at 40 ppm for reference spectra. A train of 40 Gaussian shaped pulses of $50 \mathrm{~ms}$ with $1 \mathrm{~ms}$ delay between pulses were used, for a total saturation time of $2 \mathrm{~s}$. $1 \mathrm{D}{ }^{1} \mathrm{H}$ spectra were recorded using a $1 \mathrm{~s}$ presaturation pulse with a $\mathrm{B}_{1}$ power of $200 \mathrm{~Hz}$. WaterLOGSY experiments (WL) were acquired using the ePHOGSY sequence ${ }^{33}$. WL experiments $\left({ }^{1} \mathrm{H}\right.$ spectral window $=16 \mathrm{ppm}$; relaxation delay $=3.0 \mathrm{~s}$; number of points $=16 \mathrm{~K}$, scan $=1024)$ employed a $20 \mathrm{~ms}$ selective Gaussian $180^{\circ}$ pulse at the water signal frequency and a NOE mixing time of $1 \mathrm{~s}$. Both for STD and WaterLOGSY, FIDs were multiplied by an exponential weighting $(\mathrm{lb}=5 \mathrm{~Hz})$ before Fourier transformation.

Cell lines, culture conditions, and treatments. Neuro2a cells (ATCC ${ }^{\circ}$ CCL-131 ${ }^{\mathrm{m}}$ ) were seeded in Dulbecco's modified Eagle's media (DMEM, Gibco) supplemented with FBS 10\% (Gibco), L-glutamine (Gibco) $2 \mathrm{mM}$ and penicillin/streptomycin $1 \%$ (Gibco). Depending on the experimental setting, we used 6-well, 12-well or 96-well dishes. Neuro2a were grow at $37^{\circ} \mathrm{C}$ in a humidified $5 \% \mathrm{CO}_{2}$ atmosphere. All experiments were carried out at least in triplicate. Compounds and transfections were done on cells showing $60-70 \%$ of confluence. Compounds were usually kept on cells for $48 \mathrm{~h}$; Bortezomib (BTZ) was used at $10 \mathrm{nM}$ for $6 \mathrm{~h}$ to inhibit proteasome. Transient transfections were obtained using lipofectamin LTX reagent (Thermofisher) with the following plasmids: pCMV-LacZ; pcDNA3.1 $(+)$ SOD1G93A; 77 pcCDNA3.1(+)VPS35; pCAAG-GFP according the manufacturer's instructions.

VPS35 short interference: we used Lipofectamine LTX (Thermofisher) to transfect Neuro2a cells with the following plasmids: plKO short interference scramble; TRCN0000111556 (Sh56); TRCN0000111558 (Sh58); TRCN0000111559 (Sh59), (Mission, Sigma-Aldrich). Protein and total mRNA extracts were obtained according the experimental design.

Cell survival experiments were run on 96-well plates using Cell Counting Kit-8 (CCK8) survival kit (96992-Sigma-Aldrich) according the manufacturer's recommendations. Compound 2a cytotoxicity was tested on Neuro2a cells receiving increasing amounts of compound $2 \mathbf{a}(1,10,50,100,200,500$, and 1000 $\mu \mathrm{M})$ for $48 \mathrm{~h}$. Data were acquired using an Epoch spectrophotometer equipped with the GEN5 (2.03.1) software (Agilent).

LDH cytotoxicity was run on 96-well plates using LDH-Glo ${ }^{\text {pm }}$ Cytotoxicity Assay (Promega). Briefly, Neuro2a cells were transfected with plasmids encoding pCMVLacZ; pcDNA3.1(+)SOD1G93A ${ }^{77}$ with or without VPS35 short interfering plasmids (Sh56) or compound $2 \mathrm{a}(10 \mu \mathrm{M})$. After $48 \mathrm{~h}, 5 \mu \mathrm{l}$ of supernatants were 100 -fold diluted in $\mathrm{LDH}$ storage buffer (Tris- $\mathrm{HCl} 200 \mathrm{mM}, 10 \%$ Glycerol, $1 \% \mathrm{BSA}$, Sigma-Aldrich) and used to determine $\mathrm{LDH}$, according to manufacturer's recommendations. Maximum LDH Release Control was obtained lysing untreated Neuro2a cells with $2 \mu \mathrm{L}$ of $10 \%$ Triton X-100 (Sigma-Aldrich). In each experiment we calculated $\%$ cytotoxicity $=\frac{\text { Exp.DDH release-medium background }}{\text { Max LDH release control-medium background }}$, and we run parallel positive controls treating cells with $200 \mu \mathrm{M} \mathrm{H} \mathrm{H}_{2} \mathrm{O}_{2}$. Data were acquired using a Victor3 spectrophotometer equipped with Wallac 1420 software (PerkinElmer)

Cycloheximide (CHX) assay was done on Neuro2a cells seeded in 6-well plates and incubated with compound $\mathbf{2 a}(10 \mu \mathrm{M})$ or vehicle for $24 \mathrm{~h}$. We next added CHX (Sigma-Aldrich) at $10 \mu \mathrm{g} / \mathrm{mL}$ and cells were collected at $0,2,4$, and $8 \mathrm{~h}$ for the time-course assay of VPS35 levels by WB.

Generation of human iPSC lines and derived MNs. Skin biopsies from ALS patients and healthy volunteers were performed under local anesthesia, after informed consent at San Raffaele Hospital (BANCA INSPE/8-10-19 and MND Genotipo Fenotipo/16-5-19, approved by the Ospedale San Raffaele Etic Committee). Primary fibroblasts were grown in Dulbecco's modified Eagle's medium with Glutamax I (GIBCO). Human iPS cell lines were generated using non integrating Sendai virus, maintained in feeder-free conditions in mTeSR-1 (Stem Cell
Technologies) on embryonic stem cell (HESC) Matrigel (Corning). MNs were generated following the protocol published by Du et al. ${ }^{78}$ with minimal modification. Briefly, when hiPSCs reached confluence, they have been detached using EDTA and plated 1:4 on Matrigel ES coated dishes in mTeSR-1 supplemented with ROCK inhibitor (StemMACS, Miltenyi Biotec). On the following day the medium was replaced with a chemically defined neural medium: DMEM/F12, Neurobasal medium at 1:1 ratio, $1 \%$ B27, 0.5\% N2 (all from Gibco, ThermoFisher Scientific), 1\% P/S (Gibco), 1\% Glutamax (Gibco) and $0.1 \mathrm{mM}$ Ascorbic Acid (Sigma-Aldrich). CHIR99021 (3 $\mu \mathrm{M}$, Tocris), DMH1 ( $2 \mu \mathrm{M}$, Tocris) and SB431542 ( $2 \mu \mathrm{M}$, Miltenyi Biotec) were added to the medium. The culture medium was changed every other day, until day 6 . On day 7 , cells have been dissociated with Dispase (1U/mL), split 1:4 and kept on Matrigel growth factor reduced (MaGR) for 6 days in the basal neural medium described above, supplemented with $1 \mu \mathrm{M}$ CHIR99021, $2 \mu \mathrm{M}$ DMH1, $2 \mu \mathrm{M}$ SB431542, $0.1 \mu \mathrm{M}$ Retinoic Acid (RA, Sigma-Aldrich) and $0.5 \mu \mathrm{M}$ Smoothened Agonist, (SAG, Calbiochem). On day 13, cells have been dissociated with Dispase $(1 \mathrm{U} / \mathrm{mL})$, split $1: 4$, and kept for 6 days in neural medium supplemented with $3 \mu \mathrm{M}$ CHIR99021, $2 \mu \mathrm{M}$ DMH1, $2 \mu \mathrm{M}$ SB431542, $0.1 \mu \mathrm{M}$ RA, $0.5 \mu \mathrm{M} \mathrm{SAG}$, and $0.5 \mathrm{mM}$ Valproic Acid (VPA, Tocris). To induce MN differentiation, cells were dissociated with Dispase $(1 \mathrm{U} / \mathrm{mL})$ and cultured in suspension for 6 days in neural medium with $0.5 \mu \mathrm{M} \mathrm{RA}$ and $0.1 \mu \mathrm{M} \mathrm{SAG}$ On day 25, cells were dissociated into single cell with Accumax (Sigma-Aldrich) and plated on Matrigel Growth Factor Reduced (Thermofisher) coated plates, in neural medium with $0.5 \mu \mathrm{M}$ RA, $0.1 \mu \mathrm{M}$ SAG, $0.1 \mu \mathrm{M}$ Compound E (Calbiochem) until day 35 . Half of the medium has usually been changed every other day. The karyotyping analysis was performed by ISENET Biobanking service unit in Milan, Italy (www.isenetbiobanking.com).

Immunoblotting. Lumbar SCs were dissected after mice received saline perfusion and were rapidly homogenized in the following lysis buffer: Tris- $\mathrm{HCl} 10 \mathrm{mM} \mathrm{pH} 8$, EDTA pH $81 \mathrm{mM}, \mathrm{NaCl} 100 \mathrm{mM}, \mathrm{NP} 401 \%$ and protease inhibitor cocktail (Sigma-Aldrich). Protein extracts were obtained using a tight-fitting glass Potter tissue grinder $(1 \mathrm{~mL}$; Wheaton) and then sonicated at a frequency of $20 \mathrm{kHz}(10$ times-1s). Protein lysates from cells cultures were collected from plates receiving PBS $1 \times$ washing and subsequently the lysis buffer followed by sonication. Protein concentrations were measured by BCA protein assay kit (Thermofisher) according to the manufacturer's recommendations. Ten $\mu \mathrm{g}$ of protein extract was loaded on $10 \%$ Mini-PROTEAN TGX Stain-Free precast gels for PAGE (Bio-Rad). Gel electrophoresis was performed at $100 \mathrm{~V}$ for $2 \mathrm{~h}$. Gels were transferred on Immobilon ${ }^{\oplus}$-P PVDF membrane according to the manufacturer's instructions (Millipore). Blots were blocked in 5\% BSA in Tris buffered saline plus $0.1 \%$ Tween-20 (TBS-T) for $1 \mathrm{~h}$ before receiving primary antibodies: goat $\alpha$-VPS35 1:800 (ab10099, Abcam); rabbit $\alpha$-VPS26 1:1000 (ab23892 Abcam), rabbit $\alpha$-VPS26b 1:1000 (15915-1-AP, ProteinTech); rabbit $\alpha$-VPS29 1:1000 (ab236796 Abcam); mouse $\alpha$ $\beta$ Actin 1:25000 (Sigma-Aldrich); mouse $\alpha$-Golgin97 1:1000 (Invitrogen); mouse $\alpha$ Ubiquitin 1:500 (Merk); rabbit $\alpha$-CD14 1:1000 (Bioss Inc); mouse $\alpha$-Tubulin 1:5000 (Immunological Sciences MAB-80143) overnight at $4{ }^{\circ} \mathrm{C}$ on shaker. Following several washes with TBS-T, blots were incubated in appropriate HRPlabeled secondary antibodies (Bio-Rad) for $1 \mathrm{~h}$ at room temperature. Visualization of protein bands was obtained using ClarityMax-ECL (Bio-Rad) according to the manufacturer's instructions and images were acquired on ChemiDoc (Bio-Rad). Quantifications were done using the Image Lab 6.0.1 software (Bio-Rad).

Blue-Native gel electrophoresis. G93A mice and their WT litters were injected daily with vehicle or compound $\mathbf{2 a}(10 \mathrm{mg} / \mathrm{kg}$, from day 83 to day 103). Lumbar spinal cords dissected from saline-perfused mice were lysed in Tris- $\mathrm{HCl} 10 \mathrm{mM} \mathrm{pH}$ 8, EDTA $1 \mathrm{mM} \mathrm{pH} 8, \mathrm{NaCl} 100 \mathrm{mM}$, NP40 $1 \%$ and protease inhibitor cocktail (Sigma-Aldrich). Extracts were obtained using a tight-fitting glass Potter tissue grinder ( $1 \mathrm{~mL}$; Wheaton). We incubated $250 \mu \mathrm{L}$ of each extract with $100 \mathrm{mM}$ Iodoacetamide (Sigma-Aldrich). Samples were mixed with $4 \times$ Sample NativePAGE (Thermofisher) sample buffer and the G-250 additive (Thermofisher) and proteins were resolved on native $4-15 \%$ Bis-Tris gel (Bio-Rad) with Dark Blue Cathode buffer (Thermofisher) at $150 \mathrm{~V}$ for $1 / 3$ of gel length. We replaced the running buffer with Light Blue Cathode Buffer to complete the run. At the end of the electrophoresis, gels were washed with $5 \mathrm{mM}$ tris(2-carboxyethyl)phosphine (Sigma-Aldrich) for $15 \mathrm{~min}$ and then proteins were transferred to nitrocellulose and fixed on the membrane by $8 \%$ acetic acid for 15 min. Rabbit $\alpha$-SOD1 (1:2000, Genetex) was incubated overnight as above described. Visualization of proteins was performed using ClarityMax-ECL (Bio-Rad) according to the manufacturer's instructions and images were acquired on ChemiDoc (Bio-Rad).

\section{Immunohistochemistry, immunofluorescence, and morphometric analyses.} Paraffin embedded SCs were obtained from ALS patients and non-neurological controls from the Target ALS Human Postmortem Tissue Core. Sections were stored at the INSPE tissue Bank (San Raffaele Scientific Institute). Sections were incubated with a polyclonal VPS35 antibody (1:400 Abcam ab97545) and with the polyclonal VPS26 antibody (1:200, Abcam ab23892) after rehydration and antigen retrieval (slides were cooled at $97^{\circ} \mathrm{C}$ in TRIS EDTA $\mathrm{pH}=9$ by water bath). Peroxidase-diaminobenzidine (DAB) reaction was used for detecting primary antibody, biotinylated anti-rabbit IgG $(\mathrm{H}+\mathrm{L})(1: 500$ Vector laboratories) and 
avidin-biotin complex (ABC 1:100 Vector laboratories). An operator that was blind to the disease status and demographic data subsequently evaluated these sections.

Sections from mice or glass covers containing cells were washed three times in PBS $1 \times$ (Lonza, 5 min each), and incubated in the following blocking mix: PBS $1 \times 1$ FBS 10\% (Invitrogen), BSA $1 \mathrm{mg} / \mathrm{mL}$ (Sigma-Aldrich), TritonX100 0.1\% (Sigma Aldrich), for $1 \mathrm{~h}$ at room temperature. Antibodies were diluted in blocking mix and incubated at $+4^{\circ} \mathrm{C}$ overnight according manufacturer's instructions. The following day, sections were rinsed in PBS and fluorescent secondary antibodies-i.e. never deriving from the species from which the primary antibodies are derived(Alexafluor conjugated) diluted in blocking mix, were used according to the manufacturer's instructions. Slides were incubated in Hoechst 33342 (Sigma-Aldrich) for nuclei counterstaining. When necessary, we performed antigens retrieval on tissue sections by boiling samples in $10 \mathrm{mM}$ sodium citrate $(\mathrm{pH} 6)$ for $5 \mathrm{~min}$. The following antibodies and working concentrations were used: rabbit $\alpha$-Ibal 1:500 (Wako); rabbit $\alpha$-VPS35 1:1000 (ab97545 Abcam); goat $\alpha$ VPS35 1:800 (ab10099 Abcam); rabbit $\alpha$-VPS26 1:1000 (ab23892 Abcam); rabbit $\alpha$ Sortilin 1:1000 (ab16640 Abcam); mouse a-CI-MPR 1:100 (Novus bio. NB-300514), mouse $\alpha$-NeuN 1:800 (Millipore MAB377); mouse $\alpha$-Ubiquitin 1:500 (Millipore MAB1510); mouse $\alpha$-Golgin97 1:700 (Thermofisher A21270); rabbit $\alpha$ ISLET1:1000 (ab20670 Abcam); goat $\alpha$-ChAT 1:200 (Millipore ab144p); chicken $\alpha$ GFP 1:1000 (Invitrogen); $\alpha$-SOX2 1:100 (R\&D, MAB2018); goat $\alpha$-NANOG 1:200 (R\&D, AF1997); mouse a-OCT3-4 1:500 (Santa Cruz, sc-5279); mouse a-SSEA4 1:400 (Millipore MAB4304); mouse $\alpha$-TRA1-60 1:200 (Millpore MAB4360); chicken $\alpha$-Neurofilament-medium 1:500 (Biolegend PCK-593P); rat $\alpha$-MBP 1:100 (kindly provided by Dr. A. Bolino); mouse $\alpha$-GM130 1:100 (BD biosciences, 610823); rat $\alpha$-CTSD 1:100 (R\&D system MAB1029). Tyramide Signal Amplification (TSA, PerkinElmer) was used, when appropriate, to improve fluorescent intensity in single and double immunofluorescence.

Quantification of nerves degeneration was done on sciatic nerves obtained from saline-perfused mice. Tissues were fixed in $2 \%$ buffered glutaraldehyde (Sigma-Aldrich), postfixed in $1 \%$ osmium tetroxide and cut to obtain $1 \mu \mathrm{m}$ thick sections. We stained sections with toluidine blue and specimens were blindly examined by light microscopy using $\times 40$ objective. For each nerve, we merged images to obtain the entire nerve cross section. Five consecutive nonoverlapping semi-thin sections from each sample were analyzed with NHI-Image J software (US National Institutes of Health). Degenerating fibers were counted in the entire nerve cross section.

Quantification of myelin was done on sagittal sciatic nerves by Luxol fast blue (LFB). Briefly, nerve sections were incubated the ethanol series before receiving $0.1 \%$ LFB overnight at $60^{\circ} \mathrm{C}$. Sections were then incubated $5 \mathrm{~min}$ in $0.05 \%$ lithium carbonate before receiving the ethanol series and xylene. Bright field microcopy of nerves at $\times 63$ was used for quantification. Positive myelin staining is expressed as a percentage of the total area examined.

Imaging. We used Olympus, BX51 with the following objectives: $\times 20, \times 40$, and $\times 63$ equipped with the following cameras: Leica CCD Microscope DFC3000 G and DMC2900 to obtain 16-bit light and fluorescence images (1296x966 pixels). Fluorescence images were merged using Photoshop (Adobe) CS4 or NHI-Image J software (US National Institutes of Health). We obtained confocal images using Leica SP8 equipped with $\times 40$ and $\times 64$ objectives and super-sensitive HyD detectors. We recorded each fluorescence signal as square 8-bit images $(1024 \times 1024$ pixels). Images were postprocessed to generate maximal projections of Z-stacks (acquired with a $0.4-0.8 \mu \mathrm{m}$ step) and cross-sectional profiles of the Z-stack (acquired with a $0.3 \mu \mathrm{m}$ step) and pseudo-colored using Leica Application Suite X $(2.0 .0 .14332)$

Quantification of MFI in tissue MNs. Fluorescence intensity levels of VPS35, VPS26, CI-MPR, Sortilin, CTSD and Ubiquitin were calculated using NHI-Image J software (US National Institutes of Health) according to the following protocol: stacks of confocal images were used to generate the maximal projections using the Leica Application Suite X (2.0.0.14332) software and then postprocessed by NHIImage J to crop single $\mathrm{NeuN}^{+} \mathrm{MNs}$ from the ventral horn of the spinal cord. We next performed background (calculated on adjacent slices only receiving secondary antibodies) subtraction for each channel, before applying the NHI-Image J mean filter (with radius 2.0 pixels) to calculate mean NeuN fluorescence levels in individual MNs. Using this approach, we established a region of interest (ROI) to gate single MNs. On this ROI, we measured mean fluoresce levels (MFI) of target proteins.

Morphological assessment of Golgi apparatus in Neuro2a. Golgi morphology was assessed in control or in Neuro2a cells receiving G93A plasmids with or without compound $\mathbf{2 a}(10 \mu \mathrm{M})$ as well as in GFP-transfected cells as additional control. We used Golgin97 immunofluorescence to label trans-Golgi network membranes. We classified Golgi morphology as follow: normal (polarized network), intermediate (partially fragmented) or fragmented (severely fragmented with Golgi stacks dispersed in the cytoplasm throughout). In each experiment, cells were randomly sampled across three coverslips. Golgi subclasses were expressed as a percent of the total number of Golgi scored for each experimental condition.
Micro electrode array (MEA) recordings. Primary neuronal cultures were established from the cerebral cortex of E16.5 C57BL6J embryos. Upon dissection, cells were plated on MEA biochips (60 electrode MEA biochips with $200 \mu \mathrm{m}$ electrode spacing and $30 \mu \mathrm{m}$ electrodes diameter with an integrated reference electrode, Multichannel Systems $\mathrm{GmbH}$ ) at the density of $3 \times 10^{5} \mathrm{cells} / \mathrm{MEA}$ and kept in Neurobasal medium supplemented with B27 for 14 days. At day 14 neuronal cultures were exposed to increasing concentration of compound $\mathbf{2 a}(1,3,10$, 30, and $100 \mu \mathrm{M}$ ) in Krebs-Ringer-Hepes buffer (KRH, $130 \mathrm{mM} \mathrm{NaCl}, 5 \mathrm{mM} \mathrm{KCl}$, $1.2 \mathrm{mM} \mathrm{KH}_{2} \mathrm{PO}_{4}, 1.2 \mathrm{mM} \mathrm{MgSO}_{4}, 2 \mathrm{mM} \mathrm{CaCl} 2,25 \mathrm{mM}$ Hepes, $0.6 \%$ glucose, $1 \%$ glutamine, Sigma-Aldrich). Firing activity was recorded using a pre-amplifier stage (MEA-1060-Inv-BC-Standard, gain: 55, bandwidth: $300 \mathrm{~Hz}-8 \mathrm{kHz}$, MCS GmbH) an amplification and filtering stage (FA64S, gain 20, bandwidth: $10 \mathrm{~Hz}-8 \mathrm{kHz}$, MCS GmbH) and a data acquisition device (sampling frequency: $25 \mathrm{kHz}$ ). Then, off-line signal processing was performed, and raw data were analyzed by MC-Rack Software version 4.6.2 (MCS GmbH).

Real-time PCR. Lumbar spinal tracts dissected from saline-perfused mice or Neuro2A cells were lysed to extract total RNAs using the RNeasy Mini Kit (Qiagen) according to the manufacturer's recommendations, including DNase (Promega) digestion. We synthetized the cDNA using ThermoScript RT-PCR System (Invitrogen) and Random Hexamer (Invitrogen), according to the manufacturer's instructions. The LightCycler 480 System (Roche) and LightCycler 480 SYBR Green I Master Mix (Roche) were used for real-time PCR experiments. Normalization was obtained using the housekeeping gene Histone $\mathrm{H} 3$ :

F: 5'-GGTGAAGAAACCTCATCGTTACAGGCCTGGTAC-3'

R: 5'-CTGCAAAGCACCAATAGCTGCACTCTGGAAGC-3'

The following specific primers were used for gene expression analysis: VPS35F: 5'-GTGCCGTGGTGTGCAGCATCCG-3'VPS35R: 5'-ATGCTGCATCCGCACCC AGAGC-3'VPS26A F: 5'-GCTAAGTATGAAATAATGGATGGGGC-3'VPS26A R: 5'-CTTGTTCACATCTCTCATCGTGGGG-3'VPS29F: 5'-CCAGCACATCCTCTG CACCGGC-3'VPS29R: 5'-CCACGGAATAACTTGGTGTCCGTG-3'.

Statistics. We express data as the mean value ( \pm standard error of the mean (SEM) or \pm standard deviation (SD)) of independent experiments. We assessed normality of data applying either Kolmogorov-Smirnov test (with Dallas-Wilkinson-Lille for $P$-value) or D'Agostino \& Pearson omnibus normality test. Comparisons were made using the following tests: unpaired $t$-test, one-way or two-way analysis of variance (ANOVA) tests, followed by Tukey's multiple Comparison test or by Bonferroni multiple comparison test. Statistical analyses were performed using PRISM5.01, PRISM8.4.2 (GraphPad Software, La Jolla, CA, USA) or BioVinci 1.1.5 (BioTuring Inc.). Values lower than 0.05 were considered statistically significant.

Reporting summary. Further information on research design is available in the Nature Research Reporting Summary linked to this article.

\section{Data availability}

Authors can confirm that all relevant data are included in the paper and its supplementary information. Source data are provided with this paper. The data that support the findings of this study are available from the corresponding author (luca. muzio@hsr.it), upon reasonable request. Source data from all representative blots shown in this study as well as data underlying all quantitative analysis performed in this study are provided with the manuscript as a Source Data file. Source data are provided with this paper.

Received: 26 July 2019; Accepted: 2 July 2020;

Published online: 31 July 2020

\section{References}

1. Andersen, P. M. \& Al-Chalabi, A. Clinical genetics of amyotrophic lateral sclerosis: what do we really know? Nat. Rev. Neurol. 7, 603-615 (2011).

2. Blokhuis, A. M., Groen, E. J., Koppers, M., van den Berg, L. H. \& Pasterkamp R. J. Protein aggregation in amyotrophic lateral sclerosis. Acta Neuropathol. 125, 777-794 (2013).

3. Rosen, D. R. et al. Mutations in $\mathrm{Cu} / \mathrm{Zn}$ superoxide dismutase gene are associated with familial amyotrophic lateral sclerosis. Nature 362, 59-62 (1993).

4. Bruijn, L. I., Miller, T. M. \& Cleveland, D. W. Unraveling the mechanisms involved in motor neuron degeneration in ALS. Annu. Rev. Neurosci. 27, 723-749 (2004).

5. Grad, L. I. et al. Intercellular propagated misfolding of wild-type $\mathrm{Cu} / \mathrm{Zn}$ superoxide dismutase occurs via exosome-dependent and -independent mechanisms. Proc. Natl Acad. Sci. USA 111, 3620-3625 (2014).

6. Rubinsztein, D. C. The roles of intracellular protein-degradation pathways in neurodegeneration. Nature 443, 780-786 (2006). 
7. Xie, Y. et al. Endolysosomal deficits augment mitochondria pathology in spinal motor neurons of asymptomatic fALS mice. Neuron 87, 355-370 (2015).

8. Seaman, M. N. Recycle your receptors with retromer. Trends Cell Biol. 15, 68-75 (2005)

9. Seaman, M. N., McCaffery, J. M. \& Emr, S. D. A membrane coat complex essential for endosome-to-Golgi retrograde transport in yeast. J. Cell Biol. 142, 665-681 (1998).

10. Feng, S. et al. The sorting nexin 3 retromer pathway regulates the cell surface localization and activity of a Wnt-activated polycystin channel complex. J. Am. Soc. Nephrol. 28, 2973-2984 (2017).

11. Bean, B. D., Davey, M. \& Conibear, E. Cargo selectivity of yeast sorting nexins. Traffic 18, 110-122 (2017).

12. Gallon, M. et al. A unique PDZ domain and arrestin-like fold interaction reveals mechanistic details of endocytic recycling by SNX27-retromer. Proc. Natl Acad. Sci. USA 111, E3604-E3613 (2014).

13. Zhang, P., Wu, Y., Belenkaya, T. Y. \& Lin, X. SNX3 controls Wingless/Wnt secretion through regulating retromer-dependent recycling of Wntless. Cell Res. 21, 1677-1690 (2011).

14. Seaman, M. N., Marcusson, E. G., Cereghino, J. L. \& Emr, S. D. Endosome to Golgi retrieval of the vacuolar protein sorting receptor, Vps10p, requires the function of the VPS29, VPS30, and VPS35 gene products. J. Cell Biol. 137, 79-92 (1997).

15. Arighi, C. N., Hartnell, L. M., Aguilar, R. C., Haft, C. R. \& Bonifacino, J. S. Role of the mammalian retromer in sorting of the cation-independent mannose 6-phosphate receptor. J. Cell Biol. 165, 123-133 (2004).

16. Vilarino-Guell, C. et al. VPS35 mutations in Parkinson disease. Am. J. Hum. Genet. 89, 162-167 (2011).

17. Zimprich, A. et al. A mutation in VPS35, encoding a subunit of the retromer complex, causes late-onset Parkinson disease. Am. J. Hum. Genet. 89, 168-175 (2011).

18. Zavodszky, E. et al. Mutation in VPS35 associated with Parkinson's disease impairs WASH complex association and inhibits autophagy. Nat. Commun. 5, 3828 (2014).

19. Tang, F. L. et al. VPS35 in dopamine neurons is required for ēndosome-toGolgi retrieval of Lamp2a, a receptor of chaperone-mediated autophagy that is critical for alpha-synuclein degradation and prevention of pathogenesis of Parkinson's disease. J. Neurosci. 35, 10613-10628 (2015).

20. Mecozzi, V. J. et al. Pharmacological chaperones stabilize retromer to limit APP processing. Nat. Chem. Biol. 10, 443-449 (2014).

21. Seaman, M. N. Cargo-selective endosomal sorting for retrieval to the Golgi requires retromer. J. Cell Biol. 165, 111-122 (2004).

22. Seaman, M. N. The retromer complex-endosomal protein recycling and beyond. J. Cell Sci. 125, 4693-4702 (2012).

23. Bhalla, A. et al. The location and trafficking routes of the neuronal retromer and its role in amyloid precursor protein transport. Neurobiol. Dis. 47, 126-134 (2012).

24. Kerr, M. C. et al. A novel mammalian retromer component, Vps26B. Traffic 6 , 991-1001 (2005)

25. Seaman, M. N. J. Retromer and its role in regulating signaling at endosomes. Prog. Mol. Subcell. Biol. 57, 137-149 (2018).

26. Convertino, M., Das, J. \& Dokholyan, N. V. Pharmacological chaperones: design and development of new therapeutic strategies for the treatment of conformational diseases. ACS Chem. Biol. 11, 1471-1489 (2016).

27. Chourasiya, S. S. et al. Azine-hydrazone tautomerism of guanylhydrazones: evidence for the preference toward the azine tautomer. J. Org. Chem. 81, 7574-7583 (2016).

28. Diamant, S., Agranat, I., Goldblum, A., Cohen, S. \& Atlas, D. Beta-adrenergic activity and conformation of the antihypertensive specific alpha 2-agonist drug, guanabenz. Biochem. Pharm. 34, 491-498 (1985).

29. Atkins, M. B. et al. A phase I study of CNI-1493, an inhibitor of cytokine release, in combination with high-dose interleukin-2 in patients with renal cancer and melanoma. Clin. Cancer Res. 7, 486-492 (2001).

30. Holmes, B., Brogden, R. N., Heel, R. C., Speight, T. M. \& Avery, G. S. Guanabenz. A review of its pharmacodynamic properties and therapeutic efficacy in hypertension. Drugs 26, 212-229 (1983).

31. Lipinski, C. A., Lombardo, F., Dominy, B. W. \& Feeney, P. J. Experimental and computational approaches to estimate solubility and permeability in drug discovery and development settings. Adv. Drug Deliv. Rev. 46, 3-26 (2001).

32. Mayer, M. \& Meyer, B. Characterization of ligand binding by saturation transfer difference NMR spectroscopy. Angew. Chem. Int. Ed. Engl. 38, 1784-1788 (1999).

33. Dalvit, C., Fogliatto, G., Stewart, A., Veronesi, M. \& Stockman, B. WaterLOGSY as a method for primary NMR screening: practical aspects and range of applicability. J. Biomol. NMR 21, 349-359 (2001).

34. Williams, E. T. et al. Parkin mediates the ubiquitination of VPS 35 and modulates retromer-dependent endosomal sorting. Hum. Mol. Genet. 27, 3189-3205 (2018).
35. Mourelatos, Z. et al. Fragmentation of the Golgi apparatus of motor neurons in amyotrophic lateral sclerosis revealed by organelle-specific antibodies. Proc Natl Acad. Sci. USA 87, 4393-4395 (1990).

36. Urushitani, M., Ezzi, S. A., Matsuo, A., Tooyama, I. \& Julien, J. P. The endoplasmic reticulum-Golgi pathway is a target for translocation and aggregation of mutant superoxide dismutase linked to ALS. FASEB J. 22, 2476-2487 (2008)

37. Fujita, Y. et al. Fragmentation of the Golgi apparatus of Betz cells in patients with amyotrophic lateral sclerosis. J. Neurol. Sci. 163, 81-85 (1999).

38. Sullivan, C. P. et al. Retromer disruption promotes amyloidogenic APP processing. Neurobiol. Dis. 43, 338-345 (2011).

39. Riva, N. et al. Defining peripheral nervous system dysfunction in the SOD$1 \mathrm{G} 93 \mathrm{~A}$ transgenic rat model of amyotrophic lateral sclerosis. J. Neuropathol. Exp. Neurol. 73, 658-670 (2014).

40. Kluver, H. \& Barrera, E. A method for the combined staining of cells and fibers in the nervous system. J. Neuropathol. Exp. Neurol. 12, 400-403 (1953).

41. Urushitani, M. et al. Chromogranin-mediated secretion of mutant superoxide dismutase proteins linked to amyotrophic lateral sclerosis. Nat. Neurosci. $\mathbf{9}$, 108-118 (2006).

42. Zhao, W. et al. Extracellular mutant SOD1 induces microglial-mediated motoneuron injury. Glia 58, 231-243 (2010).

43. Li, J. G., Chiu, J. \& Pratico, D. Full recovery of the Alzheimer's disease phenotype by gain of function of vacuolar protein sorting 35. Mol. Psychiatry https://doi.org/10.1038/s41380-019-0364-x (2019).

44. Li, J. G., Chiu, J., Ramanjulu, M., Blass, B. E. \& Pratico, D. A pharmacological chaperone improves memory by reducing Abeta and tau neuropathology in a mouse model with plaques and tangles. Mol. Neurodegener. 15, 1 (2020).

45. Lane, R. F. et al. Vps10 family proteins and the retromer complex in agingrelated neurodegeneration and diabetes. J. Neurosci. 32, 14080-14086 (2012).

46. Nielsen, M. S. et al. The sortilin cytoplasmic tail conveys Golgi-endosome transport and binds the VHS domain of the GGA2 sorting protein. EMBO J. 20, 2180-2190 (2001).

47. Laurent-Matha, V., Derocq, D., Prebois, C., Katunuma, N. \& LiaudetCoopman, E. Processing of human cathepsin D is independent of its catalytic function and auto-activation: involvement of cathepsins L and B. J. Biochem. 139, 363-371 (2006).

48. Miura, E. et al. VPS35 dysfunction impairs lysosomal degradation of alphasynuclein and exacerbates neurotoxicity in a Drosophila model of Parkinson's disease. Neurobiol. Dis. 71, 1-13 (2014).

49. Wootz, H., Weber, E., Korhonen, L. \& Lindholm, D. Altered distribution and levels of cathepsinD and cystatins in amyotrophic lateral sclerosis transgenic mice: possible roles in motor neuron survival. Neuroscience 143, 419-430 (2006).

50. Watanabe, M. et al. Histological evidence of protein aggregation in mutant SOD1 transgenic mice and in amyotrophic lateral sclerosis neural tissues. Neurobiol. Dis. 8, 933-941 (2001).

51. Kabashi, E. et al. Proteasomes remain intact, but show early focal alteration in their composition in a mouse model of amyotrophic lateral sclerosis. J. Neurochem. 105, 2353-2366 (2008).

52. Shah, J. J. \& Orlowski, R. Z. Proteasome inhibitors in the treatment of multiple myeloma. Leukemia 23, 1964-1979 (2009).

53. Saxena, S., Cabuy, E. \& Caroni, P. A role for motoneuron subtype-selective ER stress in disease manifestations of FALS mice. Nat. Neurosci. 12, 627-636 (2009).

54. Nakamura, N. et al. Characterization of a cis-Golgi matrix protein, GM130. J. Cell Biol. 131, 1715-1726 (1995).

55. Mourelatos, Z., Gonatas, N. K., Stieber, A., Gurney, M. E. \& Dal Canto, M. C. The Golgi apparatus of spinal cord motor neurons in transgenic mice expressing mutant $\mathrm{Cu}, \mathrm{Zn}$ superoxide dismutase becomes fragmented in early, preclinical stages of the disease. Proc. Natl Acad. Sci. USA 93, 5472-5477 (1996).

56. Cheng, X. T. et al. Characterization of LAMP1-labeled nondegradative lysosomal and endocytic compartments in neurons. J. Cell Biol. 217, 3127-3139 (2018)

57. Dahms, N. M., Olson, L. J. \& Kim, J. J. Strategies for carbohydrate recognition by the mannose 6-phosphate receptors. Glycobiology 18, 664-678 (2008).

58. Duvvuri, M., Feng, W., Mathis, A. \& Krise, J. P. A cell fractionation approach for the quantitative analysis of subcellular drug disposition. Pharm. Res. 21, 26-32 (2004)

59. Johnston, J. A., Dalton, M. J., Gurney, M. E. \& Kopito, R. R. Formation of high molecular weight complexes of mutant $\mathrm{Cu}, \mathrm{Zn}$-superoxide dismutase in a mouse model for familial amyotrophic lateral sclerosis. Proc. Natl Acad. Sci. USA 97, 12571-12576 (2000).

60. Schagger, H. \& von Jagow, G. Blue native electrophoresis for isolation of membrane protein complexes in enzymatically active form. Anal. Biochem. 199, 223-231 (1991).

61. Cullen, P. J. \& Korswagen, H. C. Sorting nexins provide diversity for retromerdependent trafficking events. Nat. Cell Biol. 14, 29-37 (2011). 
62. Small, S. A. et al. Model-guided microarray implicates the retromer complex in Alzheimer's disease. Ann. Neurol. 58, 909-919 (2005).

63. Oh, Y. K., Shin, K. S., Yuan, J. \& Kang, S. J. Superoxide dismutase 1 mutants related to amyotrophic lateral sclerosis induce endoplasmic stress in neuro2a cells. J. Neurochem. 104, 993-1005 (2008).

64. Chen, B., Retzlaff, M., Roos, T. \& Frydman, J. Cellular strategies of protein quality control. Cold Spring Harb. Perspect. Biol. 3, a004374 (2011)

65. Urushitani, M., Kurisu, J., Tsukita, K. \& Takahashi, R. Proteasomal inhibition by misfolded mutant superoxide dismutase 1 induces selective motor neuron death in familial amyotrophic lateral sclerosis. J. Neurochem. 83, 1030-1042 (2002).

66. Webster, C. P. et al. The C9orf72 protein interacts with Rabla and the ULK1 complex to regulate initiation of autophagy. EMBO J. 35, 1656-1676 (2016).

67. Corrionero, A. \& Horvitz, H. R. A C9orf72 ALS/FTD ortholog acts in endolysosomal degradation and lysosomal homeostasis. Curr. Biol. 28, 1522-1535 e1525 (2018).

68. Gonatas, N. K. et al. Fragmentation of the Golgi apparatus of motor neurons in amyotrophic lateral sclerosis. Am. J. Pathol. 140, 731-737 (1992).

69. Nishimura, A. L. et al. A mutation in the vesicle-trafficking protein VAPB causes late-onset spinal muscular atrophy and amyotrophic lateral sclerosis. Am. J. Hum. Genet. 75, 822-831 (2004).

70. Teuling, E. et al. Motor neuron disease-associated mutant vesicle-associated membrane protein-associated protein (VAP) B recruits wild-type VAPs into endoplasmic reticulum-derived tubular aggregates. J. Neurosci. 27, 9801-9815 (2007).

71. Dong, R. et al. Endosome-ER contacts control actin nucleation and retromer function through VAP-dependent regulation of PI4P. Cell 166, 408-423 (2016).

72. Stieber, A., Gonatas, J. O. \& Gonatas, N. K. Aggregates of mutant protein appear progressively in dendrites, in periaxonal processes of oligodendrocytes, and in neuronal and astrocytic perikarya of mice expressing the SOD1(G93A) mutation of familial amyotrophic lateral sclerosis. J. Neurol. Sci. 177, 114-123 (2000).

73. Morris, G. M. et al. AutoDock4 and AutoDockTools4: automated docking with selective receptor flexibility. J. Comput. Chem. 30, 2785-2791 (2009).

74. Hierro, A. et al. Functional architecture of the retromer cargo-recognition complex. Nature 449, 1063-1067 (2007).

75. Gurney, M. E. et al. Motor neuron degeneration in mice that express a human $\mathrm{Cu}, \mathrm{Zn}$ superoxide dismutase mutation. Science 264, 1772-1775 (1994).

76. Rossi, C. et al. Interleukin 4 modulates microglia homeostasis and attenuates the early slowly progressive phase of amyotrophic lateral sclerosis. Cell Death Dis. 9, 250 (2018).

77. Stevens, J. C. et al. Modification of superoxide dismutase 1 (SOD1) properties by a GFP tag-implications for research into amyotrophic lateral sclerosis (ALS). PLoS ONE 5, e9541 (2010).

78. Du, Z. W. et al. Generation and expansion of highly pure motor neuron progenitors from human pluripotent stem cells. Nat. Commun. 6, 6626 (2015).

\section{Acknowledgements}

This work was supported by a pilot GRANT from San Raffaele Scientific Institute. G.M. was supported by unrestricted financial grants from SIA (Italy) and BMW (Italy). S.E. was supported by a MARIE CURIE INVEST grant. We acknowledge The Target ALS Human Postmortem Tissue Core for providing ALS postmortem tissue slides and Lyle W. Ostrow, K Wilsbach and K Gallo for their support. We acknowledge Andrea Menegon for helping us with MEA experiments. We acknowledge Pietro Randazzo for helping us with analytical characterizations. This study is in memory of Leonardo Manzoni, a great chemist and a friend for many of us.

\section{Author contributions}

L.M. and N.R. conceived the study. L.M. did the experimental design, data analysis. L.M and P.S. wrote the manuscript. R.S. and A.F. with the help of S.E. did the in vivo and in vitro experiments and data analysis. S.E. did the western blot analysis of VPS35 in G93A mice. M.M., E.M., E.S., and L.S. performed computational experiments and modelling. D.G., L.M., and P.S. designed and synthesized compounds 3a-6a, and lead 2a L.M. and D.B. conceived and carried out NMR studies. A.Q. and N.R. did the analysis of sciatic nerves. N.R. recruited and selected the patients. L.D.F. and L.O. established iPSCderived MNs cultures. G.C. and G.M. contributed to the experimental design of the work. All authors revised the manuscript.

\section{Competing interests}

The authors declare no competing interests.

\section{Additional information}

Supplementary information is available for this paper at https://doi.org/10.1038/s41467020-17524-7.

Correspondence and requests for materials should be addressed to L.M.

Peer review information Nature Communications thanks Benjamin Wolozin, Scott Small, Wen-Cheng Xiong and the other anonymous reviewer(s) for their contribution to the peer review of this work.

Reprints and permission information is available at http://www.nature.com/reprints

Publisher's note Springer Nature remains neutral with regard to jurisdictional claims in published maps and institutional affiliations.

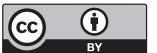

Open Access This article is licensed under a Creative Commons Attribution 4.0 International License, which permits use, sharing, adaptation, distribution and reproduction in any medium or format, as long as you give appropriate credit to the original author(s) and the source, provide a link to the Creative Commons license, and indicate if changes were made. The images or other third party material in this article are included in the article's Creative Commons license, unless indicated otherwise in a credit line to the material. If material is not included in the article's Creative Commons license and your intended use is not permitted by statutory regulation or exceeds the permitted use, you will need to obtain permission directly from the copyright holder. To view a copy of this license, visit http://creativecommons.org/ licenses/by/4.0/.

(c) The Author(s) 2020 